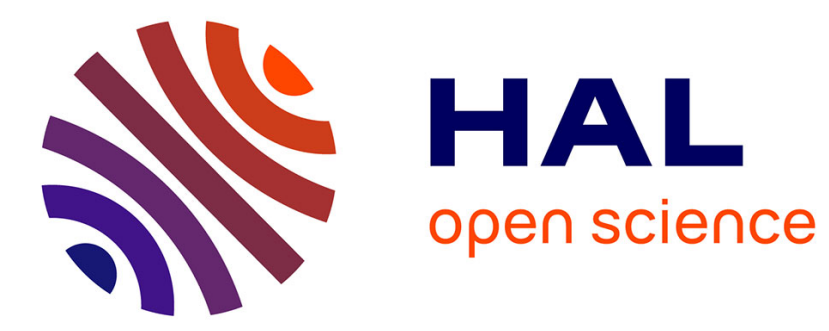

\title{
Safety focused modeling of lithium-ion batteries: A review
}

\author{
Sara Abada, Guy Marlair, A. Lecocq, M. Petit, Valérie Sauvant-Moynot, \\ François Huet
}

\section{- To cite this version:}

Sara Abada, Guy Marlair, A. Lecocq, M. Petit, Valérie Sauvant-Moynot, et al.. Safety focused modeling of lithium-ion batteries: A review. Journal of Power Sources, 2016, 306, pp.178-192. 10.1016/j.jpowsour.2015.11.100 . hal-01254406

\section{HAL Id: hal-01254406 https://hal.sorbonne-universite.fr/hal-01254406}

Submitted on 12 Jan 2016

HAL is a multi-disciplinary open access archive for the deposit and dissemination of scientific research documents, whether they are published or not. The documents may come from teaching and research institutions in France or abroad, or from public or private research centers.
L'archive ouverte pluridisciplinaire HAL, est destinée au dépôt et à la diffusion de documents scientifiques de niveau recherche, publiés ou non, émanant des établissements d'enseignement et de recherche français ou étrangers, des laboratoires publics ou privés. 


\title{
Safety Focused Modeling of Lithium-ion Batteries: a Review
}

\author{
S. Abada ${ }^{\mathrm{a}, \mathrm{b}}$, G. Marlair ${ }^{\mathrm{b}, *}$, A. Lecocq ${ }^{\mathrm{b}}$, M. Petit ${ }^{\mathrm{a}}$, V. Sauvant-Moynot ${ }^{\mathrm{a}}$, F. Huet $^{\mathrm{c}}$ \\ a IFP Energies Nouvelles, Rond-Point de l'échangeur de Solaize, F-69360 Solaize, France \\ ${ }^{\mathrm{b}}$ INERIS, parc technologique Alata, BP2, F-60550 Verneuil-en-Halatte, France \\ ${ }^{c}$ Sorbonne Universités, UPMC Univ Paris 06, CNRS, LISE, F-75005 Paris, France

\section{HIGHLIGHTS} \\ - In-depth outlook of modeling approaches for investigating Li-ion battery safety. \\ - Special focus on the thermal runaway issue and influence of ageing. \\ - Major achievements from modeling work analysed. \\ - Contextual consideration of testing for modeling construction/validation purposes.
}

\section{ABSTRACT}

Safety issues pertaining to Li-ion batteries justify intensive testing all along their value chain. However, progress in scientific knowledge regarding lithium based battery failure modes, as well as remarkable technologic breakthroughs in computing science, now allow for development and use of prediction tools to assist designers in developing safer batteries. Subsequently, this paper offers a review of significant modeling works performed in the area with a focus on the characterization of the thermal runaway hazard and their relating triggering events. Progress made in models aiming at integrating battery ageing effect and related physics is also discussed, as well as the strong interaction with modeling-focused use of testing, and the main achievements obtained towards marketing safer systems. Current limitations and new challenges or opportunities that are expected to shape future modeling activity are also put in perspective. According to market trends, it is anticipated that safety may still act as a restraint in the search for acceptable compromise with overall performance and cost of lithium-ion based and post lithium-ion rechargeable batteries of the future. In that context, high-throughput prediction tools capable of screening adequate new components properties allowing access to both functional and safety related aspects are highly desirable.

Keywords: Li-ion battery modeling, safety issues, thermal runaway, multiphysics modeling, multiscale model, battery ageing

*Corresponding author. Tel.: +33-344556370; fax: 33-344556565

E-mail address: guy.marlair@ineris.fr (G. Marlair) 


\section{Introduction}

As the world's energy consumption has been steadily increasing, efforts towards international abatements of $\mathrm{CO}_{2}$ and other greenhouse gas emissions have been made, supported by regulations and incentives. Accordingly, significant funding has promoted research at international level aiming to develop sustainable vehicles and alternative green energy sources (solar, wind, photovoltaic) that have by now entered some market reality. Intermittent character of most renewable energy sources as well as constantly increasing demand for electricity from both consumers and industry have led to recent developments and opportunities in energy storage [1]. Indeed, the availability of highly performing, cost competitive and safe electric storage systems still keeps today the weakest link in the development of many energy or power demanding applications. Among electrochemical storage systems, lithium-ion batteries (LIBs) were found to be promising candidates, especially due to their superior energy density and high specific energy over other rechargeable battery technologies as shown in Fig. 1. This high energy density, which provides a significant breakthrough from previously existing systems is due to a large potential difference between the electrodes (in the order of $3 \mathrm{~V}$ to $5 \mathrm{~V}$ per cell) [2]. Thus, after two decades of Li-ion technology marketing for portable equipment, LIBs have attracted significant attention for many more energy or power demanding applications for both electromobility and stationary applications [3]. Recently, LIBs are also growing in popularity in emerging niche markets where special duties in terms of overall performances must be fulfilled like in military, aerospace or smart grids applications.

Using lithium metal as negative electrode material for rechargeable batteries was abandoned after a while despite of better electrochemical potential windows still motivating research for the post Li-ion era [4] because the reactivity of lithium and 'lithium plating' phenomenon cause serious safety risks due to the formation of conductive dendrites leading to 
internal short circuits in the cell. This was resolved by using lithiated carbon $\left(\mathrm{Li}_{\mathrm{x}} \mathrm{C}_{6}\right)$ that has a much higher melting point than lithium metal $\left(180^{\circ} \mathrm{C}\right)$ so that LIBs are considered to be safer [5]. However, since several hundreds of large-format Li-ion cells will be needed for high power batteries like for plug-in hybrid electric vehicles (PHEVs) and pure electric vehicles (EVs), and even more power/energy demanding stationary applications, the failure of a single cell can generate a large amount of heat which can then trigger thermal runaway of neighboring cells, leading to failure throughout the battery pack [6].

Catastrophic hazardous events become more and more frequently reported by the media, such as violent venting, smoke, fire, explosion [7], although incident numbers are likely to be highly correlated with booming number of LIBs in use and their market shares [8]. The reader is referred to Table 1 to get a sample of significant incidents in airplanes and automotives. Even if incidents were shown to occur nearly everywhere on the battery value chains, it is found that the potential severity of incidents during storage, transport and recycling can be significantly higher than in end-use applications. In off-normal conditions, incidents can range from simple rupture of the cell case and leakage (more for pouch cells), to venting flammable and/or toxic gases and aerosols (hydrogen fluoride and other fluorinecontaining toxics), up to fires and explosions so that safety recalls are often used by battery manufacturers $[9,10]$. Advertised incidents often concern LIBs in aircrafts and to some extent EV car fires. Indeed, since early commercialization, the U.S. Federal Aviation Administration (FAA) has recorded some 153 incidents involving batteries of all sorts [11] among which about $50 \%$ were related to LIB or lithium metal technologies.

The combination of highly energetic materials with flammable electrolyte solutions in most LIBs progressively revealed a potential hazard of thermal runaway, especially in abuse conditions, that cause the LIB to operate outside of its thermal or electrochemical stability windows. Thermal runaway occurs if the cell temperature exceeds a critical temperature, 
above which the increase in temperature is irreversible [5]. In that case, the cell may emit a significant amount of gases from initial degradation reactions on the way forward to thermal runaway process, during which smoke is emitted, sometimes up to cell ignition and flaming combustion. Besides the related thermal hazard (fires, explosions), thermal runaway may also be responsible for mechanical effects (projection of shrapnels as well as toxic gases and vapors).

Different devices are incorporated at cell, module, and pack levels to prevent some safety issues and protect batteries from abuse conditions. For example, at the cell level, internal protection devices are used, such as positive temperature coefficient (PTC) expansion disks, current-interrupt devices, or shutdown separators between the anode and cathode, to limit high current, as well as cell vents to prevent excessive gas pressure, or fusible links in high-capacity cells $[12,13]$. To prevent internal short-circuits in the cell, another way introduced by Matsushita (Panasonic) consists in using a thermally stable porous ceramic coating between the electrodes able to resist at temperatures higher $\left(>160^{\circ} \mathrm{C}\right)$ than conventional separators $\left(130{ }^{\circ} \mathrm{C}-150{ }^{\circ} \mathrm{C}\right)$ [14]. At module and pack levels, sometimes at powered equipment level, another key safety device, designated as the battery management system (BMS), is generally operating to manage and control various functions and settings (voltage, current, temperature). From internal measurements, advanced BMS may also estimate some parameters, such as the state-of-charge (SOC) and state-of-health ( $\mathrm{SOH}$ ), which may greatly contribute to keep the battery in an optimal operational state [15]. In addition, various thermal management strategies are investigated mainly for LIBs applications in commercial HEVs and EVs [16].

For a long time, battery safety studies have been mainly performed through experimental approaches supported by post-mortem battery analyses from field failures as well as by safety and abuse tolerance tests [3]. However, these approaches have quickly faced 
limitation because of the various complex phenomena involved in batteries. Moreover, the experimental tests are destructive so that the cost in battery samples for testing is significant. Additionally, delivering battery samples for testing is hardly technically feasible at early stage of development of large batteries. Consequently, using modeling and simulation able to predict battery safety and performance in various contexts of end-use is of great help to design new batteries, especially as databases created from experiments conducted previously are now available to validate predictive models and achieve proven accuracy of simulation data.

In this paper, a review on safety-focused modeling approaches is presented. Indeed, the literature shows that numerous investigations targeting safety issues of secondary lithiumion batteries were reported in the last decade, and studies on battery modeling at cell/module/pack levels, especially in abuse conditions, clearly appeared essentially after 2012. As electrochemical and thermal models are considered as a starting point to predict the battery behavior and tolerance in abuse conditions, nominal electrothermal modeling, including ageing and mechanical/stress modeling, is considered first. Studies on thermal runaway modeling are then reported. The experimental thermal and electrical tests and analysis methods used for model validation are finally described.

\section{Battery operation modeling including ageing}

The purpose of this section is to quickly present the main modeling approaches developed in previous studies attending to improve understanding of battery behavior and to address the challenges in designing reliable, durable and safe batteries. Models provide insights in the comprehension of physical mechanisms and simulation of battery behavior in controlled conditions. Various physical phenomena (electric, electrochemical, thermal, mechanical stress) occur at different levels in the battery system, from atomistic level to pack system (Fig. 2). Therefore describing all of them in great detail in a battery model requires 
considerations of trade-offs between potential level of improvement in prediction capability and extra costs due to increased computational requirements and longer simulation time.

Three scales can be considered in battery modeling according to the phenomena of interest, from material scale to whole battery system design:

- at material level (microscopic length scale), the elementary processes, such as for example charge transfer, Li diffusion through the active material particles and in the electrolyte, or particle deformation, are described;

- at the cell level, the transport, thermodynamic, thermal, mechanical, and kinetic phenomena are described at a mesoscopic scale to determine the cell performance. At this level, microscale physical models are usually mathematically reduced for efficiency sake;

- at the pack level, the cells are undifferentiated and their behavior is averaged to address issues relating to their integration in more complex systems (vehicles, grids...).

Furthermore, at each scale, two groups of models can be distinguished according to their level of predictability:

- The empirical models, which are fitted to experimental data with polynomial, exponential, power laws, logarithmic, and trigonometric functions, without direct consideration of physicochemical mechanisms [17]. Empirical models, such as those with electrical equivalent circuits $[18,19]$, have simple construction and operate at fast computational speed [20]; however, since they are fitted to data measured under specific operating conditions, they often poorly predict the Li battery behavior under other conditions.

- The analytical models (electrochemical, thermal, and multiphysics coupled models) potentially operating at various scales and under multidimensional approaches including chemical/electrochemical kinetics and transport ( $\mathrm{Li}$, electron) phenomena and relying on the use of appropriate sets of equations. These models can accurately predict the behavior of LIBs. Several types of analytical modeling have been developed depending on their 
complexity, from simple models to more sophisticated ones in which more physics is added to achieve higher level of prediction accuracy [17].

In the next sections, the electrochemical, ageing, and thermal main sub-models developed and published in the scientific literature are briefly described and multiphysics coupled models are then considered.

\subsection{Electrochemical models}

Numerous electrochemical models of lithium-ion batteries have been developed since the pioneering work of Newman's group on a cell model based on a lithium anode, a solid polymer electrolyte, and an insertion composite cathode [21]. Several authors reviewed the main electrochemical models of lithium-ion batteries and their use towards the design of better batteries [17,22-24]. In the porous electrode approach, the Pseudo Two-Dimensional (P2D) model, in which the solid material in each electrode is assumed to comprise identical spherical particles, is the reference in terms of integration of the various physical processes occurring in a battery and prediction capabilities. However, it requires very powerful computing resources so that mathematical reduction of the model was proposed by some authors, such as the porous electrode model with the polynomial approximation (PP model), in which the concentration within each spherical particle of each electrode was approximated with a parabolic profile, and the single particle model (SPM) [24-26], in which each electrode is represented by a single spherical particle of area equal to that of the active area of the solid phase in the porous electrode. Both latter models cited (PP, SPM) are much faster than the P2D model but they do not account for all the physical processes in the cell, thus they have limitations in prediction of battery performance.

Further developments of the P2D model may be found in the literature with the aim of taking into account specific features of the electrode materials, or improving the modeling of ionic conductivity and transport in the electrolytic and solid phases, or reducing the 
calculation time from use of simplified equations, lumped parameters, or reduced reaction scheme for ageing kinetics, etc.

The general framework of the P2D model is here briefly summarized. Reactions usually considered for $\mathrm{Li}$ insertion-deinsertion are the following (where MO refers to metal oxide):

$$
\begin{array}{ll}
\mathrm{Li}_{1-y} \mathrm{MO}+y \mathrm{Li}^{+}+y \mathrm{e}^{-} \underset{\text { charge }}{\stackrel{\text { discharge }}{\longleftarrow}} \mathrm{LiMO} & \text { at the positive electrode } \\
\mathrm{LiC}_{6} \underset{\text { charge }}{\stackrel{\text { discharge }}{\rightleftarrows}} x \mathrm{Li}^{+}+x \mathrm{e}^{-}+\mathrm{Li}_{1-x} \mathrm{C}_{6} & \text { at the negative electrode }
\end{array}
$$

The electrochemical kinetics and transport phenomena in the cell (Fig. 3) are governed by non-linear differential-algebraic equations (DAEs), which are summarized in Table 2 [27].

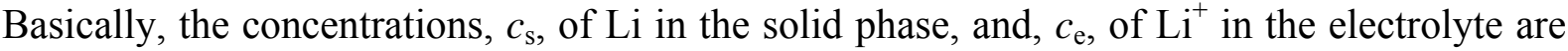
given by mass transport Equations (3) and (4), respectively. Charge conservation (Equations (5) and (6)), allows the potentials, $\phi_{\mathrm{s}}$ and $\phi_{\mathrm{e}}$, of the two phases to be calculated in each electrode, and the electrochemical kinetics is modelled by the Butler-Volmer Equation (7). The cell voltage, $V(t)$, at time $t$

$V(t)=\phi_{\mathrm{S}}(L)-\phi_{\mathrm{S}}(0)$

can be expressed as the sum of the thermodynamic potentials, $U_{\mathrm{p}}$ and $U_{\mathrm{n}}$, the overpotentials, $\eta_{\mathrm{p}}$ and $\eta_{\mathrm{n}}$, and the electrolyte phase potential difference at the two current collectors, $\phi_{\mathrm{e}}(L)$ $\phi_{\mathrm{e}}(0)[27,28]$.

Several techniques have been used for modeling electrochemical systems, the most common being the finite difference method (FDM), the finite volume method (FVM), and the finite element method (FEM). However, solving the non-linear differential equations of the P2D model requires long computational times, so that modeling efforts aimed at reducing the complexity of the problem have been performed during the past 20 years to get faster 
simulations $[17,22,24,29-34]$. However, as mentioned in several papers, reduced-order models (ROM) are often accurate enough for low charge and discharge current rates but they still have disadvantages in terms of precision at high current rates $[24,29,34]$.

\subsection{Ageing modeling}

Many studies have been focused on understanding and modeling the ageing phenomenon in LIBs during the past two decades since ageing leads to energy loss and power fade due to the increase of cell resistance. Multiple and complex ageing mechanisms have been described for various positive and negative electrode chemistries [34-37]. The more important ones on the carbonaceous negative electrodes concern the quality of the solid electrolyte interphase (SEI) growing at the electrode/electrolyte interface as a result of electrolyte decomposition, the deposition of $\mathrm{Li}^{+}$as metallic $\mathrm{Li}$ at high charging currents, which can lead to short circuits, and the loss of active material for several reasons, inducing capacity fade. As for negative electrodes, ageing occurs on positive metal oxide electrodes from degradation of the active material, structural disorder due to change in volume of the material as a consequence of $\mathrm{Li}$ insertion/extraction, phase transition leading also to mechanical stress, or surface film formation due to electrolyte decomposition. All these ageing mechanisms are influenced by cycling and storage operating conditions, which have a strong impact on battery life-time and performance.

Empirical, semi-empirical, and physics-based models have been proposed in the literature to predict capacity fade, power fade, discharge voltage, or residual charge from experimental data measured in various operating conditions $[18,38-46]$. These works have been aimed at diagnosing the effect of ageing on the lifetime performance degradation of various LIBs during calendar or cycle life, mainly for electric vehicle applications. Among the different LIB degradation mechanisms, the continuous formation of the SEI layer over the surface of the negative electrode, which is the most often reported ageing mechanism, have 
been described by physics-based models[40,42,44-47]. An overview of the most frequent mathematical equations describing this ageing phenomenon is displayed in Table 3 [41,44]. The electrochemical kinetics of the parasitic reaction of SEI formation described by Equation (15) can be expressed by Butler-Volmer's Equation (16). The mass balance of Li in the solid material of the negative electrode is given in Equation (17) where $i_{\text {int }}$ is the current density due to $\mathrm{Li}$ intercalation, and $i_{\mathrm{s}}$ is the current density due to SEI formation. Equation (18) describes the transport of solvent molecules by convection and diffusion inside the SEI layer, whereas Equation (19) expresses the growth rate of this layer as a function of the current density of the solvent reduction.

\subsection{Thermal modeling}

Performance, life and safety of LIBs are affected by operation history and storage temperature. Hence, regardless their power/energy performances and applications envisioned, LIBs need to be managed thermally at each level of functional assembly, from cell to pack. Therefore, thermal properties, heat generated and heat dissipated at each level of the battery system must be addressed in a model able to predict the thermal behavior of the battery under different operational conditions.

To achieve a comprehensive analysis, these models must consider all geometrical parameters of the battery pack, such as the layered-structure of the cell stacks, the case of the battery system, or the gap between cells, because these parameters influence temperature variations between the cells in the battery. As a consequence, thermal modeling must take into account the environmental conditions of the battery including the boundary conditions of heat transfer by convection, conduction and radiation, especially at the battery pack level. This is a prerequisite in order to develop thermal management strategies able to control the temperature inside the pack for safety issues. Many papers have been published on battery thermal analysis, most of them including experimental works and numerical simulations performed 
with FDMs [48-50], FVMs [51-53], FEMs [54-57], or computational fluid dynamics (CFD) methods [29,58-61].

Thermal models of batteries were first mostly based on the energy balance between the energy produced inside the battery and the energy dissipated from it:

$\frac{d}{d t} Q_{\text {accumulation }}=\rho C_{\mathrm{p}} \frac{\partial T}{\partial t}=\dot{Q}_{\text {generated }}-\dot{Q}_{\text {dissipated }}$

where $\rho$ is the cell density, $C_{\mathrm{p}}$ the mean heat capacity, and $T$ the cell temperature. $Q_{\text {accumulation }}$ represents the energy accumulated in the battery per unit cell volume, which is the source of temperature change in the battery, while $Q_{\text {generated }}$ represents the heat generated during battery operation, and $Q_{\text {dissipated }}$ the heat loss due to conduction, convection and radiation.

\subsubsection{Heat generation during battery operation}

Heat generation inside the battery is mainly caused by charge transport and chemical reactions during charge/discharge routine operations in normal use. Besides, heat generation may also arrive from uncontrolled conditions where temperature may increase, or because of the occurrence of undesirable side reactions at elevated temperatures. Thus, heat generation is generally described in thermal models as the sum of reversible and irreversible heat sources [16,62-68]. As illustrated in Fig. 4, the reversible heat is produced by the change in entropy due to the open-circuit voltage (OCV) variation with temperature, while the irreversible heat is due to the overpotential heating, which includes ohmic loss, charge transfer overpotential and mass transfer limitation, and to the heat of mixing, caused by the formation (or relaxation) of concentration gradients when the current is set or turned off. Enthalpy heating is another source of irreversible heat caused by material phase changes due to diffusion of lithium ions in the solid phase.

Bernardi et al. [62] first presented a general thermal model based on a thermodynamic energy balance for a complete battery cell with the exception of the current collectors. The 
heat generation rate is given by the following equation when the temperature is assumed to be constant through the cell but varies with time:

$\dot{Q}_{\text {generated }}=-i V-\sum_{\mathrm{j}} i_{\mathrm{j}} T^{2} \frac{d \frac{U_{\mathrm{j}, \mathrm{avg}}}{T}}{d T}+\dot{Q}_{\text {mixing }}+\dot{Q}_{\text {phase change }}$

where $i$ is the current per unit cell volume, $i V$ is the electrical work and the following term is the enthalpy of reaction summed over all simultaneously occurring reactions. $U_{\mathrm{i}, \text { avg }}$ is the theoretical open-circuit potential (OCP) for reaction $\mathrm{j}$ evaluated at the average compositions. Details about the phase-change term, which is commonly neglected, can be found in Ref. $[62]$.

Later, Rao and Newman proposed a new method for calculating the heat-generation rate in insertion battery systems from the general energy balance by using enthalpy potentials and neglecting the mixing and phase-change terms [69]. The effects of side reactions were then incorporated in Rao and Newman's energy balance by Botte et al. [22] to explain the thermal behavior of a cell. In many studies, the mixing and phase-change heat terms are not considered so that the following simplified expression of the heat generation rate is often encountered in the literature[16,48-50,61,64,66,70-75]:

$\dot{Q}_{\text {generated }}=i(U-V)-i\left(T \frac{\partial U}{\partial T}\right)$

where $U$ is the OCV,$V$ the cell voltage. The first term in the right-hand-side of this equation takes into account the overpotential sources while the second one is the entropic heat.

However, some authors found it necessary to add terms in Equation (22) to model the heat generation rate more precisely. For example, Xiao and Choe [68] reported that the enthalpy heating can contribute for more than half of the total irreversible heat generation in the cell, so that an enthalpy heating term, $j^{\mathrm{Li}}\left(U_{\mathrm{avg}}-U_{\mathrm{s}, \mathrm{e}}\right)$, where $j^{\mathrm{Li}}$ is the current per unit cell 
volume, $U_{\text {avg }}$ the average equilibrium potential inside the particle, and $U_{\mathrm{s}, \mathrm{e}}$ the equilibrium potential at the surface of the particle, must be added in Equation (22). The heat of mixing due to the generation and relaxation of concentration gradients in both the electrolyte and insertion compound, is usually considered to be negligible in commercial LIBs since they have good transport properties and limited concentration gradients $[16,63,68,75,76]$. When large concentration gradients are expected, the heat of mixing term added in Equation (22) is given by the following expression [62]:

$\dot{Q}_{\text {mixing }}=\sum_{\mathrm{i}}\left(\bar{H}_{\mathrm{i}}-\bar{H}_{\mathrm{i}}^{\mathrm{avg}}\right) \frac{\partial c_{\mathrm{i}}}{\partial t}$

where $\bar{H}_{\mathrm{i}}$ is the partial molar enthalpy of species i, $c_{\mathrm{i}}$ its concentration, and $\bar{H}_{\mathrm{i}}^{\text {avg }}$ the partial molar enthalpy of species $i$ evaluated at the volume-average concentration. The integral is calculated over the total volume of the cell, including both the insertion electrodes and the electrolyte.

\subsubsection{Heat dissipation during battery operation}

Heat is dissipated in the environment through three well known mechanisms of heat transfer: conduction, convection, and radiation. Conduction corresponds to the transfer of thermal energy due to the presence of temperature gradient inside the battery. The heat dissipation rate by conduction through the cell until its boundaries is equal to $-\nabla \cdot k(\nabla T)$, where $T$ is the temperature and $k$ the isotropic or nonisotropic thermal conductivity of the cell $[49,56,73,77,78]$. At the cell boundaries, both convection and radiation must be considered. The natural or forced convection heat transfer rate can be expressed as $h_{\mathrm{c}}\left(T_{\mathrm{s}}-T_{\mathrm{amb}}\right)$ where $h_{\mathrm{c}}, T_{\mathrm{s}}$, and $T_{\mathrm{amb}}$ are the convective heat transfer coefficient, surface and ambient temperature, respectively $[49,62,71,73,77,78]$. The rate of radiative heat transfer depends on the forth power of the surface temperature, $\varepsilon \sigma\left(T_{\mathrm{S}}^{4}-T_{\mathrm{amb}}^{4}\right)$, where $\sigma$ is the Stefan-Boltzmann constant 
and $\varepsilon$ denotes the emissivity of the cell surface[49,77,78]. However, when the surface temperature is only slightly higher than ambient temperature, linearization gives a simpler expression, $4 \varepsilon \sigma T_{\mathrm{amb}}\left(T_{\mathrm{s}}-T_{\mathrm{amb}}\right)$, similar to that of the convection heat transfer rate. As a consequence, the rate of both convection and radiation heat transfers is often written as $h_{\text {comb }} A\left(T_{\mathrm{s}}-T_{\mathrm{amb}}\right)$, where $h_{\mathrm{comb}}$ is a combined heat transfer coefficient.

\subsubsection{Governing thermal equations}

In the core of the battery cell, heat is dissipated by conduction only, so that the thermal energy balance over any differential volume may be written, according to Equation (20):

$\rho C_{\mathrm{p}} \frac{\partial T}{\partial t}=\dot{Q}_{\text {generated }}+\nabla \cdot k(\nabla T)$

while at each boundary of the cell, the condition relative to the convective and radiative heat transfers is given by the following equation $[49,70,78,79]$ :

$$
-k_{\mathrm{n}} \frac{\partial T}{\partial \mathrm{n}}=h_{\mathrm{c}}\left(T_{\mathrm{s}}-T_{\mathrm{amb}}\right)+\varepsilon \sigma\left(T_{\mathrm{s}}^{4}-T_{\mathrm{amb}}^{4}\right)
$$

in which the left-hand side term represents the conductive heat flux from the cell core in the direction $n(n=x, y$, and $z)$.

Thermal models are now often based on a three-dimensional (3D) representation. Even if one-dimensional (1D) models are sometimes sufficient to simulate the thermal behavior of single cells in approaches based on homogenization with averaged properties, they bear significant limitations for large cells, modules or packs, or for taking into account the thermal influence of the cell case and electrical current-collector tabs. 3D thermal modeling is indeed now possible with modern computing techniques and many recent works studying heat dissipation in battery packs are based on CFD approaches $[58,60,61,80-83]$. Thermal models are needed to analyze the characteristics of temperature fields as a function of battery design parameters, charge and discharge rates, environmental air flow rate, state-of-charge, etc. They 
also enable efficient dissipation of the generated heat to avoid cell temperature increase, which can lead to thermal runaway in extreme cases. This explains why they have been employed to investigate various different cooling strategies, especially at the battery pack level, to achieve good thermal management [19,58-60,77,80-94].

\subsection{Multiphysics coupled models}

Multiphysics models in the literature include coupled or decoupled electrochemical and thermal simulation approaches, sometimes involving in addition ageing phenomena [4345]. Thermal models are directly linked to electrochemical models since heat generation results from the physical and (electro-) chemical phenomena occurring in the battery (Equation (20)). Moreover, several mass transport and kinetic parameters of the electrical model are taken as temperature dependent variables, generally following an Arrhenius law $[27,28,46,95-97]:$

$$
\Psi=\Psi_{\text {ref }} \exp \left(\frac{E_{\mathrm{a}}(\Psi)}{R}\left(\frac{1}{T_{\text {ref }}}-\frac{1}{T}\right)\right)
$$

where $\Psi$ is the temperature-dependent parameter, $E_{\mathrm{a}}$ is its activation energy, $R$ is the ideal gas constant, and $T_{\text {ref }}$ is a reference temperature, often $25^{\circ} \mathrm{C}$.

A great variety of formulations have been developed for multiphysics models with various computer codes to obtain good predictive tools sufficiently fast to be implemented in battery management systems. Averaged (0D) or multidimensional parameterization has been used for single- or multi-scale domains (particle, electrode, cell, cell case, electrical terminals and tabs, module, and pack). In recent works, coupling P2D or simplified 1D electrochemical models and 3D thermal models appears to be the trend to take into account the non-uniformity of the temperature inside the battery $[29,52,56,57,67,98,99]$. For large LIB cells or packs, coupled or decoupled sub-models are sometimes used in each modeling domain to describe 
the electrical and thermal behavior of the battery. For example, Lee et al. [98] defined 3 submodels (1D spherical particle model, 1D porous electrode model, and 3D single potential-pair continuum model for the cell to solve heat and electron transfer in the wound structure) to study the thermal behavior of cylindrically-wound large format LIB cells. At the pack level, Sun et al. [60] combined 3D thermal and electrochemical coupled cell/module sub-model with an equivalent circuit sub-model linking the current and voltage at battery cell terminals and a 1D network pack sub-model to estimate the surface temperature of the individual cells and the lumped temperature variation across the entire battery pack.

Coupled electrochemical and thermal (EC-T) models have been developed to gain a better understanding of the thermal behavior of Li-ion cells, modules and packs under a wide range of operating conditions, in order to achieve better design, management and predictions of various electrical and thermal parameters. EC-T models and comparison with experimental data have been used for a wide variety of investigations, such as for the estimation of the reversible and irreversible heat sources $[53,57,68,85]$, the surface temperature and core temperature of cells $[67,95,100,101]$, the effect of cooling on discharge capacity $[52,60]$, the influence of the active particle size and electrode thickness on the heat generation rate [97], the limitations of pulse power operations [28], the effect of temperature on the $\mathrm{Li}$ concentration gradient in both solid and liquid phases $[53,96]$, the influence of ageing on the power and capacity losses at different temperatures [44-46,102], the importance of heat dissipation via the metal current collectors that causes large temperature gradients across the cells affecting their capacity [56,57], the influence of the number, location, and size of electrical tabs on the cell on its performance and life $[29,98,99]$, etc.

\section{Thermal runaway modeling}

Integrating coupled multiphysics models in predictive computer tools is the most recent trend in scientific works focusing on battery safety. This interest is due to the number 
of safety related phenomena, including thermal runaway events that result from strongly combined exothermic electrochemical reactions, mass and thermal transfer processes, as well as mechanical issues (stress deformation, delamination...). Battery thermal runaway is considered by all stakeholders as the most dramatic consequence potentially occurring in a battery system, following abnormal conditions of use, or in fewer cases resulting from manufacturing defaults. Modeling efforts dealing with triggering events such as internal or external short-circuits, overcharge, overdischarge, or overheating, will be reviewed first. In the subsequent section, the modeling works of the consequences of these events, especially thermal runaway at cell and pack levels, will be reported.

\subsection{Modeling of the triggering events of battery failure}

\subsubsection{Short circuit}

Among the activation conditions leading to thermal runaway, externally or internally triggered short circuits are well-identified electrical abuse conditions [6]. Indeed, internal short circuit was found to be the most studied triggering event from experimental and modeling perspectives since it is difficult to simulate it in practice and subsequently to model it. In addition, following damaging consequences such as gassing, Joule heat release, etc, appear rapidly. One major internal short-circuit issue in LIBs was identified in early stages of LIB commercialization as resulting essentially from manufacturing defects [103]. More recent investigations led to the conclusion that different types of internal shorts may develop in LIBs during use or in other situations such as charging [104]. Significant modeling efforts on the different internal short-circuit scenarios that can occur between different cell components were performed by Maleki and Howard [105], Santhanagopalan et al. [103], Kim et al. [104], Fang et al. [106], Feng et al. [107] and recently by Zhao et al. [108] and Chiu et al. [109]. According to the accurate localization of the internal short potentially arising, the following typology of short circuit has been defined and investigated: 
1. Internal short circuit between metals (current collector foils: aluminum and copper).

2. Internal short circuit between electrodes (positive and negative materials).

3. Internal short circuit between aluminum current collector and the negative electrode (bypassing the positive electrode).

It appears from literature that achieving adequate knowledge of those different types of shortcircuit events keeps crucial and major achievements in this field have been obtained through the development of significant experimental works, aimed to understand major short-circuit mechanisms on the one hand and validate appropriate relating physical models on the other hand.

By combining modeling and experimental validations, both Santhanagopalan et al. [103] and Fang et al. [106] showed that the short circuit between the aluminum current collector and the negative electrode produced the highest subsequent heat generation, and led to the maximum local cell temperature. It was, therefore, considered as the most dangerous short.

In research devoted to battery safety, a number of electrochemical-thermal coupled models have been proposed to consider short circuit $[103,108-110]$. These sophisticated models account for more realistic heat propagation mechanisms as compared to the isolated thermal model used in studies by Fang et al. [106] and Maleki and Howard [105]. For example, Yamauchi et al. [110] developed an electrical, physical and thermal coupled model to study the conditions of thermal runaway in nail-penetrating tests, in which the internal short circuit is due to the contact between the current collectors of the positive and negative electrodes. However, one limitation of this work lies in the fact that the battery cell geometry was much simplified. A further significant improvement was proposed by Santhanagopalan et al. [103] who introduced more realistic battery boundary conditions. Nonetheless, no 3D current distribution across the cell was reported in these works in which the internal 
electrochemical process model is simply coupled to the simulation of the overall thermal response of the battery. This latter limitation was at least partially overcome by Arnold et al. [111] who developed a pseudo 3D electrochemical-thermal model in which the energy balance equation was coupled to several 1D electrochemical models between the positive and negative current collectors and to $2 \mathrm{D}$ current collector models in order to study the current and temperature distributions through a small spot area.

Beyond the influence of type of contact between oppositely charged materials, internal short circuits are also influenced substantially by other battery characteristics such as cell capacity, SOC, specific surface area of the negative electrode and impact of lithiation [103], in addition to miscellaneous environmental parameters $[105,110,112]$.

\subsubsection{Mechanical abuse}

One of the main concerns about LIBs safety, especially in automotive applications, is their response to mechanical stresses (e.g. following a car crash or induced by vibrations). Consequently, studies have been performed to model the behavior of LIBs under mechanical stress and develop more mechanical stress resistant battery designs. The target is generally focused on the preservation of LIB cell integrity under heavy constraints [13], a goal which finds clear justification as the aftermath of the Chevy Volt post-crash tests fire events in 2012 [113]. For such purposes of model development, a series of constrained compression tests and crashworthiness analyses at micro and macro scales $[114,115,116]$ have been carried out. Tests results gave large data sets of mechanical properties of both LFP/C and LCO/C cells and cell individual components. These data have been used to calibrate mechanical abuse models developed by Ali et al. [117,118]. Their models describe battery responses to mechanical stresses at cell and module level using a finite element model, where compressive mechanical behavior is characterized by buckling and densification of cell components. These models are targeting to mock up mechanical stresses representative of normal use and 
therefore they do not claim to hold prediction capability of the activation time of potential thermal runaway triggered as a result of mechanical deformation of cell and relating components. So far, the only publications known by us dealing with mechanical abuse modeling linking deformation calculation to short-circuit phenomenon activation in a cell are those published by Sahraei and co-workers [119-123]. In their modeling approach, short circuit is considered induced by the failure of the separator which, in turn is caused by the fracture of electrodes [123]. Subsequently, the onset of short circuit in the cell is predicted in relation with the corresponding breaking force and punch displacement on the cell using a finite element model [119-123].

\subsubsection{Overheating}

Oven exposure testing is frequently used by stakeholders to evaluate the overall thermal stability of Li-ion cells and the related thermal runaway threats. This is both costly and time consuming for manufacturers or end users. Thus, many studies aimed to develop predictive modeling of the externally-induced thermal abuse response of LIBs. For example, Hatchard et al.'s thermal model [124] can predict the response of new cells and/or electrode materials to oven induced thermal stress exposure on the basis of kinetics data simply derived from the thermal response obtained from accelerated rate calorimetry (ARC) and differential scanning calorimetry (DSC) studies. In another work, Hatchard et al. [125] showed the importance of considering radiant heat transfer in oven abuse testing.

\subsubsection{Overcharge}

The overcharge abuse conditions can all the more severely affect battery integrity as additional energy is added to the cell beyond full charge, which may result from malfunctioning of the charging unit. An overcharge test was first simulated by Spotnitz and Franklin [126] who introduced overcharge in their model by adding the following specific generation rate term, $\dot{Q}_{\text {over }}$, to the cell energy balance given by Equation (24): 
$\dot{Q}_{\text {over }}=i_{\mathrm{OC}}^{2} \frac{L_{\mathrm{i}}}{\sigma_{\mathrm{i}}}$

where $L_{\mathrm{i}}$ is the thickness of material i (negative, positive, separator), $i_{\mathrm{OC}}$ the overcharge current density and $\sigma_{i}$ the conductivity of material i. Simulations of overcharge conditions with this model showed that the subsequent thermal runaway was mainly driven by metallic lithium reacting with solvent in the cell.

\subsection{Modeling of activated thermal runaway and follow-up consequences}

Thermal runaway develops dramatically in the battery as soon as heat produced in abuse conditions is in excess to the heat dissipation capacity of the system. Besides the modeling works focused on the understanding of thermal runaway triggering modes, modeling efforts have been and are still underway to comprehensively investigate thermal runaway by itself as the main adverse process potentially leading to cascading thermal, chemical and mechanical hazardous events depending on many battery parameters. After studies on the battery behavior under regular operating conditions (baseline case), many studies have actually been carried out in that direction, first at cell level, then at module/pack level.

\subsubsection{Cell level}

Two general approaches are used to simulate the cell behavior under thermal abuse conditions. First, calorimetry-based models were widely studied at Sandia National Laboratories through Richard and Dahn's works [127,128]. In this approach, which requires calorimetric measurement at material and cell levels, the thermal properties of the cell components are characterized by reaction rate equations using Arrhenius thermal activation energy terms. By contrast to this approach mostly of experimental nature, the second one is more analytical since it relies on the development of chemical reactions. Chemical-based models offer a wide range of prediction capabilities comparing to the calorimetry-based 
models. However, this approach requires to identify the chemical reactions at the origin of each prevailing thermal event and, moreover, specific kinetic parameters such as the reaction rate and activation energy of each reaction have to be determined. According to their increasing dimensional order, the well-known modeling works at cell level under abuse conditions are summarized hereinafter from the earliest to latest.

Firstly, Hatchard et al. [124] proposed a thermal model based on kinetics data obtained from ARC and DSC studies. This model is able to predict the response of new cells and/or electrode materials in oven tests. Later, Spotnitz and Franklin [126] proposed an extended model of the thermal runaway process of LIBs based on the important exothermic reactions occurring in abuse conditions: 1) SEI layer decomposition, 2) reaction of intercalated lithium with electrolyte $\left(T>120^{\circ} \mathrm{C}\right)$, 3) reaction of lithiated carbon with fluorinated binder, 4) electrolyte decomposition $\left.\left(T>200^{\circ} \mathrm{C}\right), 5\right)$ positive active material decomposition, and 6$)$ lithium metal reactions. With the corresponding estimates of reaction heats and kinetic parameters taken from literature, they simulated a variety of abuse conditions of high-rate batteries (oven, overcharge, short circuit, nail, crush); however, their results were not compared with experimental data for validation. For their part, Tanaka and Bessler [129] included both exothermic SEI formation and decomposition mechanisms in their 1D thermoelectrochemical model of a Li-ion cell at elevated temperatures. The model, which was used to simulate DSC of the negative electrode, was parameterized and validated up to $250^{\circ} \mathrm{C}$ with Du Pasquier et al.'s DSC experimental results [130].

Three-dimensional models are required to simulate a localized heat release and the propagation of the chemical reactions inside a cell. Kim et al. [131] developed a 3D thermal model in which the following terms have been integrated in the energy balance Equation (24) to account for the heat release due to the exothermic abuse reactions in the cell, with the 
exception of reactions involving lithium metal (which would be important in an overcharge test) and combustion reactions.

$\dot{Q}_{\mathrm{abuse}}=\dot{Q}_{\mathrm{SEI}}+\dot{Q}_{\mathrm{ne}}+\dot{Q}_{\mathrm{pe}}+\dot{Q}_{\mathrm{ele}}+\dot{Q}_{\mathrm{nb}}$

where the volumetric heat generation rates from the SEI decomposition reaction, $\dot{Q}_{\text {SEI, from }}$ the reaction between the negative active material, $\dot{Q}_{\text {ne, }}$ from the reaction between the positive active material, $\dot{Q}_{\text {pe }}$, from the electrolyte decomposition, $\dot{Q}_{\text {ele }}$, and from the negative active material and the binder, $\dot{Q}_{\mathrm{nb}}$, are considered. The volumetric heat release rate in each cell component is calculated according to the following relation [124]:

$\dot{Q}_{\mathrm{i}}=H_{\mathrm{i}} W_{\mathrm{i}} R_{\mathrm{i}}$

where $R_{\mathrm{i}}$ is the reaction rate in cell component $\mathrm{i}, H_{\mathrm{i}}$ the specific heat release, and $W_{\mathrm{i}}$ the specific active material content. Kim et al.'s model was validated with oven tests performed on $\mathrm{LiCoO}_{2} /$ graphite cells. Recently Lopez et al. [132] developed a thermal runaway model based on thermal abuse reactions proposed by Kim et al. [131] and calibrated with corresponding thermal parameters identified by Hatchard et al. [125]. They validated this model with both $\mathrm{LCO} / \mathrm{C}$ cylindrical and combination of spinel and nickel oxide cathode prismatic spiral-wound cells, by use of oven tests results obtained in the experimental work of Hatchard et al. [125]. Through different simulation conditions, they found that the severity of thermal runaway increased with increased oven temperature and decreased convection coefficient [132]. By altering the heat released during the electrolyte decomposition they identified the genuine contribution of the electrolyte combustion on abuse exothermic reactions. This modification allows a better agreement with experimental tests especially involving the prismatic spiral-wound cells where electrolyte combustion occurs after venting.

Guo et al. [133] developed a 3D electrochemical-thermal coupled model for evaluating the temperature distribution in large capacity and high power LIBs in thermal abuse 
conditions. Large capacity cells are more sensitive to thermal runaway because of higher energy content. In this multiphysic model, the impact of thermal abuse conditions is simulated by implementation of a "side reactions term" in the energy balance equation. Heat generation rates of those side reactions in the simulations were estimated from experimental measurements as function of temperature. The model predictions were shown to be in good agreement with oven test results for $3.2 \mathrm{~V} / 55 \mathrm{Ah} \mathrm{LiFePO}_{4} /$ graphite cells. The model could also predict the occurrence of thermal runaway accurately.

At cell level, combustion reactions (e.g. electrolyte solvent, other combustible materials) are not commonly considered in the effort of modeling the thermal abuse reactions, while recently Lopez et al. [132] found that an electrolyte combustion reaction must be integrated in some cases as mentioned previously. According to Spotnitz and Franklin's model [126], the exothermic reaction of the fluorinated binder with lithiated carbon in the negative electrode does not play a significant role in thermal runaway. Side reactions accounting for ageing are also generally ignored.

\subsubsection{Pack Level}

Modeling at module/pack level is aimed at apprehending the risks of propagation of cell thermal runaway within a battery pack, the goal being to confine the damage to the environment of the failing cell and prevent further destruction or disability in the module or the entire pack. Modeling the propagation of thermal runaway within modules and packs has been and still is the subject of numerous investigations [6,14,134,135]. Spotnitz et al. [14] developed a model to estimate the stability of a 8-cell module when one cell goes into thermal runaway. For simplification, they assumed that the self-heating rate given by ARC experiments produced a normal curve as a function of temperature for each cell and a single temperature was considered for each cell, hence neglecting temperature gradients within the cells. By initiating thermal runaway in a given cell, their investigations revealed that 
propagation could occur depending on the ability of the neighboring cells to dissipate and absorb heat. On their side, Pesaran et al. [136] mentioned the impact of cell-to-cell interconnects on the propagation of thermal runaway and revealed that heat conduction through electrical connectors dominates the heat transfer between cells within a module. Later, to help in the design of abuse-tolerant LIB modules, Smith et al. [6] developed a coupled thermal/electrical model of a commercial 18650 cell that was integrated into a module with 16 cells in parallel, considering cell-to-cell electrical and thermal interactions via conduction, convection, and radiation. The cell electrical response was modeled with an equivalent circuit with separate circuit elements capturing the interaction of the cells with the PTC current-limiting devices and the jellyroll behavior. According to the authors, their model was shown to be suitable for assessing battery safety design margins. Indeed the NASA research group compared the safety design on two different module configurations [137] using Smith et al.'s approach of thermal runaway propagation modeling from one cell to neighboring ones within a module. To simulate a single cell behavior they used the thermal abuse model developed by Chiu et al. [109]. Additionally, they took into account air conduction, convection and radiation heat transfers between cells within a module. Through different simulation conditions they found that thermal runaway may be mitigated in their studied module configuration by suppressing direct thermal contact between cells using for example a phase change interstitial material or an aluminum heat spreader. Recently, during the $225^{\text {th }}$ ECS meeting, the NREL group presented their 3-D electrochemical-electricalthermal model [137] aimed at studying thermal runaway propagation from cell to cell through a LIB module. The model integrates an electrochemical-thermal performance model, an abuse reaction kinetics model of cell components, and an electrical-thermal network models at module level. The model claims to be capable of capturing cell and module response to thermal, mechanical and electrical abuse for various electrical series-parallel configurations. 
It should be noticed that for large format applications (automotive and stationary), performing propagation tests was, until recent past, the only way to evaluate the risks of thermal runaway outside the faulty cell, while modeling capability at that level is just emerging. Small cell simulations, likewise that performed by Spotnitz et al. [14], have not been directly applied to large modules and packs. Thus, to scale up the thermal runaway effect from the use of single cell model to module/pack assemblies, the dissipation heat within the module shall be considered in addition to heat transfer between neighboring cells. The key concern in present modeling effort remains to be able to predict, and subsequently prevent or mitigate, the effects of thermal runaway occurring in LIBs. Thus, models must be improved by considering both thermal and electrochemical behaviors of cells in abuse conditions $[138,139]$ and taking into account ageing effects [139].

\section{Experimental approach for safety model construction and validation}

The experimental approach remains a crucial point in the development of all types of models since it aims at producing data for both model construction and validation. This is of course also the case regarding battery safety and thermal runaway to obtain a reasonable level of confidence in the model predictions [17]. However, most system variables are not directly measurable during charge-discharge cycles and, therefore, it is mandatory to calibrate the battery models. The requested input parameters in all thermal models and thermal abuse models are mainly the heat generation rate and the battery thermal properties [140].

\subsection{Thermal properties characterization}

Thermal characterization tests are performed to identify thermal properties both at material and battery system level. Thermal characterization includes the estimation of heat capacity, thermal conductivity and diffusivity.

\subsubsection{Heat capacity estimation}


The heat capacity at cell, module and battery pack level is a critical parameter that can be assessed by different methods. It can be estimated from the specific heat capacity of cell/module components from the following equation:

$$
C_{\mathrm{p}, \text { average }}=\sum_{i=1}^{n} \frac{C_{\mathrm{p}, \mathrm{i}} m_{\mathrm{i}}}{\sum_{i=1}^{n} m_{\mathrm{i}}}
$$

where $m_{\mathrm{i}}$ and $C_{\mathrm{p}, \mathrm{i}}$ are, respectively, the mass and heat capacity of component i. Use of Equation (30) relies on the knowledge of all heat capacities of key cell or module components. Alternatively, NREL uses a single-ended (one test chamber) conduction calorimeter [134] to estimate an average specific heat at various current rates, temperatures, and SOCs, expressed by Equation (31):

$$
C_{\text {p,average }}=\frac{Q}{M_{\text {tot }}\left(T_{\text {initial }}-T_{\text {final }}\right)}
$$

where $Q$ is the heat lost or gained by the battery in going from temperature $T_{\text {initial }}$ to $T_{\text {final }}$ and $M_{\text {tot }}$ is the mass of the cell/module. The calorimeter, initially manufactured by Calorimetry Sciences Corporation, was later improved, calibrated and commissioned by NREL for module and small pack testing to validate thermal abuse models and thermal management policies [134].

To estimate the heat capacity, Forgez et al. [76] used a simplified equivalent circuit (Fig. 5) modeling the energy balance equation, in which two resistors, $R_{\text {in }}$ and $R_{\text {out, }}$ a capacitor, $C_{\mathrm{p}}$, and a current source represented the heat transfer phenomena, the heat accumulation term and the heat source term, respectively. From a single current-pulse experiment measuring the surface temperature as a function of time, the equivalent internal heat transfer resistor, $R_{\text {in }}$, and the equivalent external heat transfer resistor, $R_{\text {out }}$, could be determined from the thermal steady-state part, while the heat capacity, $C_{\mathrm{p}}$, was determined from the transient part. Their method relies on an optimization process based on a least-square 
regression on the surface temperature, using the values of $R_{\text {in }}$ and $R_{\text {out }}$. Heat capacity values from current-pulse experiments with different current magnitudes were compared, and a noticeable error on the $C_{\mathrm{p}}$ value around $6 \%$, including those on $R_{\mathrm{in}}$ and $R_{\text {out }}$, was estimated. Using their model, the authors could estimate the internal temperature of the battery cell from its surface temperature. More recently, Fleckenstein et al. [141] presented a non-destructive thermal impedance spectroscopy method for thermal characterization of battery cells, following the pioneering work by Barsoukov et al. [142] who introduced frequencydependent thermal impedance functions for that purpose. Using a thermal battery model, the theoretical transfer function between the internal heat generation and the resulting battery surface temperature was calculated and fitted in the Nyquist plot to the transfer function measured on a cylindrical high-power Li-ion cell. Compared to the estimation with conventional thermal characterization methods, differences respectively of $5 \%$ in the specific heat capacity and $12 \%$ in the heat conductivity of the cell were obtained.

\subsubsection{Thermal conductivity estimation}

Casing and core parts are two distinct regions of the LIB, subsequently inducing anisotropic thermal conductivity in the battery. According to the ASTM E1225-13 standard [143], the thermal conductivity of a material can be determined by measuring the temperature drop across it that is generated by an applied heat flux on one of its surfaces. Using this method, the effective thermal conductivity, $K_{\mathrm{i}}$, of a cell component can be calculated in each direction $(i=x, y, z$, or $r, \theta, z)$ according to the Fourier equation [134].

$$
K_{\mathrm{i}}=\frac{q \Delta l_{\mathrm{i}}}{\Delta T}
$$

where $q$ is the surface heat flux density, $\Delta l_{\mathrm{i}}$ is the thickness of a sample in direction $i$, and $\Delta T$ is the temperature difference. The thermal conductivity of a cell component can also be derived from the thermal diffusivity of the cell component according to Equation (33): 
$K(t)=\alpha(t) C_{\mathrm{p}}(t) \rho(t)$

where $\alpha$ is the thermal diffusivity that describes the speed of heat propagation by conduction during temperature changes with time, $C_{\mathrm{p}}$ is the heat capacity, and $\rho$ the density of the component. The thermal diffusivity is estimated with the Flash Diffusivity Method [134,144146]. This experimental technique, based on the application of a high-intensity short-duration heat pulse (laser, induction), was described for the first time by Parker et al. [147].

\subsection{Estimation of heat generation rate}

The development of experimental methods and diagnosis tools is essential to assess the impact of each heat source in the battery, in particular for the design of appropriate battery thermal management systems. Commercial calorimeters are widely used to measure heat generation rates in batteries even if they have limited heat transfer capabilities and do not provide the dynamics needed for step charging and discharging of cells [68]. In models, the heat generation rate is generally described as the sum of reversible and irreversible heat source terms.

Overpotential heat, which includes ohmic loss, charge-transfer overpotential, and mass-transfer limitation, is often the main component of irreversible heat. In practice, it is typically estimated by direct calculation of the overpotential using the OCV and the cell voltage [16]. It is also the product of the current by the overpotential resistance, which can be measured either from the slope of the battery voltage-current characteristics at a given SOC, or from the voltage change after current interruption for some time, or from $a c$-impedance at a specific frequency $[148,149]$. Additional irreversible heat generation terms, entropy heating and heat of mixing, are sometimes considered in the literature. As mentioned in Section 2, enthalpy heating is obtained from the product of the reaction rate times a potential difference so that no specific additional measurement technique is needed. Heat of mixing is due to 
change of ionic concentration when switching the current on or off. So called dynamic calorimeters, as that designed by Xiao and Choe to qualify two purpose-built thermoelectric devices [68], are therefore necessary to measure fast heat generation rates.

The reversible heat comes from the change of entropy. Its generation rate (last term in Equation (22)) is proportional to the entropic heat coefficient $\partial U / \partial T$, so the most straightforward and easiest method to estimate this parameter consists in measuring the OCV variation with temperature at a fixed SOC $[16,139,148,149]$. However, this method is timeconsuming to ensure steady-state OCV in the procedure. Thomas and Newman [150] proposed a method to minimize the effect of self-discharge that can be important at long waiting times and high SOC [150]. For a given SOC, the cell voltage measured during relaxation at constant temperature is subtracted from the voltage data during relaxation at changing temperature. This yields a linear relationship between voltage and temperature, even at high SOC, from which the entropic heat coefficient can be deducted. The entropic heat coefficient can also be evaluated by calorimetry-based methods. For example, it can be measured from the heat production difference between the calorimeter charge and discharge data if the irreversible heat can be supposed to remain constant upon charge and discharge [149]. Comparison of these different methods essentially showed similar and consistent results [16].

\subsection{Kinetics of degradation reaction inside the cell}

As reported in the previous section, the thermal runaway of LIBs is due to exothermic reactions produced by the decomposition of the different components of the cell. Spotnitz and Franklin [126] published an extensive review of experimental data from DSC and ARC highlighting possible exothermic decomposition reactions of all components in the LIB, including the binder and all active materials. Experimental investigations on the thermal stability of electrodes, electrolytes and electrode/electrolyte interfaces have been carried out, 
in which the heat generation rate of decomposition reactions and self-heating reactions in abuse conditions were reported. Several investigators used DSC measurements in order to assess the thermal stability of LIB negative electrodes [124,130,151-154], positive electrodes $[151,154-156]$, and electrolytes $[151,157-160]$. Some of these studies have been used in model validation in the context of thermal runaway. For example, Tanaka and Bessler [129] compared their simulated DSC measurements of the negative electrode with Du Pasquier et al.'s DSC results [130].

Accelerated rate calorimetry is another technique widely used to study both battery safety and performance $[72,127,128,148,151,156,161-163]$. Indeed, ARC is convenient to perform battery tests under abuse (thermal abuse, overcharge, overdischarge) and in-use (battery cycling) conditions for modeling support purposes. In particular, ARC allows access to battery cycling performance, heat capacity, temperature evolution, and exothermic reaction rate data. As examples, Richard and Dahn [127,128] showed how ARC results could be used to predict short-circuit and oven exposure profiles for 18650 cells, while Gnanaraj et al. [163] evaluated the thermal stability of various electrolytes and identified endothermic and exothermic reactions in the temperature range $40{ }^{\circ} \mathrm{C}-350{ }^{\circ} \mathrm{C}$. The authors claimed that the ratio between the heating and reaction rates is a factor impacting significantly the sensitivity of DSC measurements, the ARC measurements being more sensitive for thermal investigations. On their side, Al-Hallaj et al. [72] determined the onset of thermal runaway temperature for commercial lithium-ion cells at different OCV. The thermal stability of aged batteries was also investigated using ARC; a comparative study between fresh and aged samples showed that the thermal runaway of aged samples was triggered earlier than with fresh samples [164]. In a study by ARC concerning high-power 18650 LiNiMnCo batteries, fresh and aged by high-rate and low temperature cycling, Fleischhammer et al. [165] showed 
a strong influence of the ageing history on the safety behavior, the main cause of safety hazard being metallic Li plating on the negative electrode in their case.

A fire calorimeter device, called Tewarson calorimeter or Fire Propagation Apparatus (FPA- ISO 12136), may be used to characterize the combustion behavior of materials and Liion cells [166-169] through sample mass-loss measurement and on-line analysis of combustion gases such as $\mathrm{O}_{2}, \mathrm{CO}, \mathrm{CO}_{2}$, hydrogen halides, $\mathrm{HCN}, \mathrm{NO}_{\mathrm{x}}, \mathrm{SO}_{\mathrm{x}}$, and aldehydes. $\mathrm{By}$ use of such calorimeter, key data like the heat release rate, the effective heat of combustion, the mass of burnt products and toxic gas emitted can be calculated. From experiments with the FPA, Ribière et al. [166] investigated the fire-induced hazards of 2.9 Ah Li-ion pouch cells while Eshetu et al [167] studied the fire behavior of $\mathrm{LiPF}_{6}$ and $\mathrm{LiN}\left(\mathrm{SO}_{2} \mathrm{~F}\right)_{2}$-based electrolytes used in rechargeable LIBs. The FPA was also used by Diallo et al. $[168,169]$ to investigate the thermal and combustion hazard profiles of various ionic liquids (ILs). Whereas their study somewhat questioned the "non flammability" often claimed too generically for this large family of chemicals, it also revealed that the actual combustibility of ILs highly varies according to their chemical structure and showed that ILs generally present good to remarkable resistance to ignition. These studies may therefore help to formulate IL-based electrolytes safer than the common carbonate organic mixtures used in LIBs. They can also be used to calibrate abuse models involving combustion of cell components. In addition, they may provide appropriate input data needed to model fire gas dispersion following battery cell, module or pack fire scenario, and estimate related fire-induced toxicity.

Robinson et al. [170] applied an original approach combining thermal imaging, X-ray tomography and electrochemical impedance spectroscopy approach to study the thermal characteristics of single 18650 spiral wound lithium nickel manganese cobalt (NMC) oxide Li-ion cells. While X-ray tomography provides a 3D structural map of the cell, thermal imaging is used to characterize the non-uniform temperature distribution within the cell, the 
most significant heating effect being observed at the positive cap in that case. Infrared thermal imaging is widely used to validate thermal models at cell, module, and system level [134]. Other techniques, such as scanning electron microscopy (SEM), X-ray diffraction, and X-ray photoelectron spectroscopy, are often used to identify events leading to thermal runaway and provide a diagnosis of cell evolution during the abuse tests. These techniques have also a clear potential to assist the construction or the validation of future models able to predict internal mechanical disorders such as delamination or stress deformation. Quite recently, high-speed synchrotron, X-ray computed tomography and radiography techniques were used, in conjunction with thermal imaging, to develop a new in-operando diagnosis approach for studying the evolution of internal structural damage and thermal behavior during thermal runaway and failure of $18650 \mathrm{NMC}$ cells due to external thermal abuse [171]. Dynamic visualization of structural degradation under various abuse conditions accessible with these techniques might greatly support the development of multiphysics models of LIB failures accounting for structural deterioration, breakdown and material ejection in order to help in the design of safer batteries.

\subsection{Abuse tests}

Abuse tests are defined in battery safety standards and regulations developed by many organizations such as the United Nations, the Institute of Electrical and Electronics Engineers (IEEE), the International Electrotechnical Commission (IEC), the International Organization for Standardization (ISO), the National Aeronautics and Space Administration (NASA), the Japan Automobile Research Institute (JARI), SAE International, Underwriters Laboratories (UL), Verband der Automobilindustrie (VDA), etc. [172]. Abuse tests are mainly classified into three categories:

- Thermal abuse tests: simulated fuel fires, thermal stability, overheat, etc.

- Electrical abuse tests: short circuit, overcharge, overdischarge, etc. 
- Mechanical abuse tests: mechanical shock, vibration, drop, nail penetration, immersion, crush, etc.

Some of these tests have been used to calibrate and validate thermal models such as the thermal stability test in adiabatic calorimeter, the oven test, the external short-circuit test, or to simulate internal short circuits by nail penetration, small indentation and cell pinching. These tests are briefly discussed hereinafter.

Thermal stability tests, which consist in a multi-step heating process of the battery, are usually performed in adiabatic calorimeters like ARCs. The objective of these tests is to determine the maximum temperature at which a battery can be safely used and evaluate the thermal runaway reaction kinetics via the onset of self-heating. Oven tests generally consist in exposing samples at controlled steady temperature conditions and are widely used to validate thermal abuse models [124,134]. Electrical abuse tests, such as the external short-circuit test, are also investigated to assess the behavior of LIBs under such conditions and to validate associated models. As an example, NREL used such a test to validate an external short-circuit model at pack level [6]. As it is obviously easy to protect batteries from external shortcircuits, experimental works devoted to short-circuit modeling have rapidly focused on internal short circuits much more complex to address. Different experimental methods for simulation of internal short circuits have been reported in the literature. However, most of these methods faced difficulties in introducing small isolated internal short circuit in a reproducible manner because it requires disassembling the cell in charged condition for preparation of the short event and then re-assembling the test cell. For example, Santhanagopalan et al. [103] inserted a large nickel particle between different layers of the cell to generate the three types of short circuit described in Section 3.1, while Fang et al. [106] drilled a hole of $2 \mathrm{~mm}$ in diameter in the separator to create the internal short. Besides, the 
nail penetration test has been introduced to simulate mechanically internal short circuits and validate the corresponding models $[105,107,109,110,173]$.

Overcharge tests (charge above the manufacturer's high voltage specification or too fast charging process with excessive currents) and overdischarge tests (discharge below the manufacturer's low voltage specification) are also performed to trigger thermal runaway reactions in LIBs in such abuse conditions. Experimental investigations to characterize the effects of overcharge and overdischarge on performance and thermal stability of LIB cells were reported by several researchers [174-180]. The root cause of thermal runaway reaction during overcharge of $\mathrm{LiCoO}_{2}$ cells was attributed to the reaction of the overcharged negative electrode and the electrolyte solvent at high temperature induced by the exothermic reaction between the positive electrode and the electrolyte [174]. Other authors observed inorganic species originating from the cathode and fixed on the anode side of separators disassembled from overcharged cells, which suggests that thermal runaway at overcharge might be due to micro shorting through the separator, hence accelerating side reactions on the anode side $[177]$.

\section{Conclusion}

In this survey study concerning modeling of secondary lithium-ion batteries, battery operating models, including ageing under normal operating conditions, and thermal runaway models potentially occurring in incidental situations, have been identified. They have been carefully examined in terms of overall methodology taken, consideration with genuine multiphysics associated phenomena, prediction capabilities and relating limitations, as well as development and validation modes. Due to the recent booming activity in electric energy storage modeling, it may be anticipated that the work cannot be considered at time of publishing as exhaustively covering all models of interest in the context of battery safety which, as a reminder, is a key issue for successful energy storage of the future. One 
conclusion of this work is that models simulating normal operating conditions of batteries integrating the effect of ageing are more widespread as compared to models capable of simulating LIBS dynamic responses to abuse operating conditions. Most frequent models of the latter type generally focus on the triggering events characterizing abuse conditions for a LIB than modeling the thermal runaway process by itself through propagation of heat within the cell. Up to now only one multiphysics and multiscale operating model has been developed by the NREL research team, this model being able to predict the thermal runaway propagation from one cell to its neighbors within the module. To our knowledge, no abuse model has taken into account the effect of ageing in conjunction with the occurrence of abuse conditions, and no abuse model is available commercially, each research group willing to keep intellectual property of their model, and therefore mostly still proceeding to further in-house development. It is clear from our analysis that the benchmarking of existing models to appraise impartially their predictive capabilities and overall performance characteristics through common simulation exercises or in view of replicating single set of experimental results is still missing and would help to set level of confidence for their pertinent use. It can be anticipated that such benchmarking would be highly recommended for further validation of usable models. Competent authorities would likely consider such a procedure as mandatory, before any official recognition of computer models results in the context of battery safety certification processes for critical applications of energy storage based on Li-ion batteries. Recent initiatives federating a diversity of skills, like the recent creation of the Joint Center for Energy Storage Research (JCESR) in the USA [181], or the French national network RS2E in France [182] are likely to promote fast progress in lithium based battery modeling in the coming years, and promote computed aided tools based on appropriate sets of complex physical models as key instrument to develop safer batteries, in association with appropriate testing for their construction and validation. As safety will for sure keep a key issue in energy 
storage for the post Li-ion battery era, according to the need of meeting still better performances (capacity, life cycle, cost...), it is believed that the effort in modeling electrochemical storage is worth to be emphasized for a long time. Whereas the development of multiphysics and multiscale models is one way worth to proceed for optimizing safety management at module or pack levels, ab initio calculations (eg. density functional theory DFT - calculations) might rapidly raise interest of stakeholders of energy storage development for screening appropriate key components for new chemistry batteries at early stage of design [183]. In this context, integrating functionality criteria but also safety criteria was also found an emerging and appropriate way of investigation in the field of battery modeling. 


\section{References}

[1] N.-S. Choi, Z. Chen, S.A. Freunberger, X. Ji, Y.-K. Sun, K. Amine, G. Yushin, L.F. Nazar, J. Cho, P.G. Bruce, Angew. Chem. Int. Ed. 51 (2012) 9994-10024.

[2] B. Scrosati, K.M. Abraham, W.A. van Schalkwijk, J. Hassoun, Lithium Batteries: Advanced Technologies and Applications, John Wiley \& Sons, 2013.

[3] S. Santhanagopalan, K. Smith, J. Neubauer, G. H. Kim, A. Pesaran, M. Keyser, Design and Analysis of Large Lithium-Ion Battery Systems, Artech House, 2015.

[4] W. Xu, J. Wang, F. Ding, X. Chen, E. Nasybulin, Y. Zhang, J.-G. Zhang, Energ. Environ. Sci. 7 (2014) 513-537.

[5] Y. Guo, Safety: Thermal Runaway in: J. Garche (Ed.), Encyclopedia of Electrochemical Power Sources, Elsevier, Amsterdam, 2009, Vol. 4, pp. 241-253.

[6] K. Smith, G.-H. Kim, E. Darcy, A. Pesaran, Int. J. Energ. Res. 34 (2010) 204-215.

[7] D. Lisbona, T. Snee, Process Saf. Environ. Prot. 89 (2011) 434-442.

[8] L. Hollmotz, Safety of lithium ion batteries in vehicles: state of the art, risks and trends, Proceedings of the $23^{\text {rd }}$ International Technical Conference on the Enhanced Safety of Vehicles, Seoul, South Korea, 2013.

[9] http://www.greencarreports.com/news/1074491_a123-systems-to-recall-electric-carbattery-packs-for-fisker-others, accessed on 12.07.15.

[10] http://www.consumerreports.org/cro/news/2012/07/nikon-recalls-more-than-200-000camera-batteries-due-to-burn-hazard/index.htm, accessed on 12.07.15.

[11] http://www.faa.gov/about/office_org/headquarters_offices/ash/ash_programs/hazmat/air carrier info/media/battery incident_chart.pdf, accessed on 12.07.15.

[12] D. Doughty, E.P. Roth, Interface, The Electrochemical Society (Summer 2012) 37-44.

[13] J. Jeevarajan, Safety of Commercial Lithium-Ion Cells and Batteries, in: G. Pistoia (Ed.), Lithium-Ion Batteries, Elsevier, Amsterdam, 2014, pp. 387-407.

[14] R.M. Spotnitz, J. Weaver, G. Yeduvaka, D.H. Doughty, E.P. Roth, J. Power Sources 163 (2007) 1080-1086.

[15] F. Badin, Hybrid Vehicles: From Components to System, Ed. Technip, Paris, France, 2013.

[16] T.M. Bandhauer, S. Garimella, T.F. Fuller, J. Electrochem. Soc. 158 (2011) R1-R25.

[17] V. Ramadesigan, P.W.C. Northrop, S. De, S. Santhanagopalan, R.D. Braatz, V.R. Subramanian, J. Electrochem. Soc. 159 (2012) R31-R45. 
[18] B.Y. Liaw, R.G. Jungst, G. Nagasubramanian, H.L. Case, D.H. Doughty, J. Power Sources 140 (2005) 157-161.

[19] J. Li, M.S. Mazzola, J. Power Sources 237 (2013) 215-228.

[20] A.A. Franco, RSC Adv. 3 (2013) 13027-13058.

[21] M. Doyle, T.F. Fuller, J. Newman, J. Electrochem. Soc. 140 (1993) 1526-1533.

[22] G.G. Botte, V.R. Subramanian, R.E. White, Electrochim. Acta 45 (2000) 2595-2609.

[23] P.M. Gomadam, J.W. Weidner, R.A. Dougal, R.E. White, J. Power Sources 110 (2002) $267-284$.

[24] S. Santhanagopalan, Q. Guo, P. Ramadass, R.E. White, J. Power Sources 156 (2006) $620-628$.

[25] M. Guo, G. Sikha, R.E. White, J. Electrochem. Soc. 158 (2011) A122-A132.

[26] D. Zhang, B.N. Popov, R.E. White, J. Electrochem. Soc. 147 (2000) 831-838.

[27] E. Prada, D. Di Domenico, Y. Creff, J. Bernard, V. Sauvant-Moynot, F. Huet, J. Electrochem. Soc. 159 (2012) A1508-A1519.

[28] K. Smith, C.-Y. Wang, J. Power Sources 160 (2006) 662-673.

[29] M. Guo, R.E. White, J. Power Sources 221 (2013) 334-344.

[30] K.A. Smith, C.D. Rahn, C.-Y. Wang, Energ. Convers. Manage. 48 (2007) 2565-2578.

[31] P.W.C. Northrop, V. Ramadesigan, S. De, V.R. Subramanian, J. Electrochem. Soc. 158 (2011) A1461-A1477.

[32] L. Cai, R.E. White, J. Electrochem. Soc. 156 (2009) A154-A161.

[33] J.C. Forman, S. Bashash, J.L. Stein, H.K. Fathy, J. Electrochem. Soc. 158 (2011) A93A101.

[34] P.W.C. Northrop, B. Suthar, V. Ramadesigan, S. Santhanagopalan, R.D. Braatz, V.R. Subramanian, J. Electrochem. Soc. 161 (2014) E3149-E3157.

[35] J. Vetter, P. Novák, M.R. Wagner, C. Veit, K.-C. Möller, J.O. Besenhard, M. Winter, M. Wohlfahrt-Mehrens, C. Vogler, A. Hammouche, J. Power Sources 147 (2005) 269-281.

[36] P. Verma, P. Maire, P. Novák, Electrochim. Acta 55 (2010) 6332-6341.

[37] M. Broussely, Ph. Biensan, F. Bonhomme, Ph. Blanchard, S. Herreyre, K. Nechev, R.J. Staniewicz, J. Power Sources 146 (2005) 90-96.

[38] M. Broussely, S. Herreyre, P. Biensan, P. Kasztejna, K. Nechev, R.J. Staniewicz, J. Power Sources 97-98 (2001) 13-21. 
[39] S. Brown, Diagnosis of the lifetime performance degradation of lithium-ion batteries: focus on power-assist hybrid electric vehicle and low-earth-orbit satellite applications, Kungliga Tekniska Högskolan, Stockholm, 2008.

[40] P. Ramadass, B. Haran, R. White, B.N. Popov, J. Power Sources 123 (2003) 230-240.

[41] M. Safari, M. Morcrette, A. Teyssot, C. Delacourt, J. Electrochem. Soc. 156 (2009) A145-A153.

[42] M. Safari, C. Delacourt, J. Electrochem. Soc. 158 (2011) A1436-A1447.

[43] N.D. Williard, Degradation analysis and health monitoring of lithium-ion batteries, PhD thesis, University of Maryland (USA), 2011.

[44] E. Prada, D. Di Domenico, Y. Creff, J. Bernard, V. Sauvant-Moynot, F. Huet, J. Electrochem. Soc. 160 (2013) A616-A628.

[45] A. Awarke, S. Pischinger, J. Ogrzewalla, J. Electrochem. Soc. 160 (2013) A172-A181.

[46] L. Liu, J. Park, X. Lin, A.M. Sastry, W. Lu, J. Power Sources 268 (2014) 482-490.

[47] M.B. Pinson, M.Z. Bazant, J. Electrochem. Soc. 160 (2013) A243-A250.

[48] Y. Chen, J.W. Evans, J. Electrochem. Soc. 140 (1993) 1833-1838.

[49] S.C. Chen, C.C. Wan, Y.Y. Wang, J. Power Sources 140 (2005) 111-124.

[50] M.-S. Wu, K.H. Liu, Y.-Y. Wang, C.-C. Wan, J. Power Sources 109 (2002) 160-166.

[51] C. Park, A.K. Jaura, Dynamic thermal model of Li-ion battery for predictive behavior in hybrid and fuel cell vehicles, SAE Technical Paper 2003-01-2286, 2003, http://dx/doi.org/10.4271/2003-01-2286.

[52] J. Christensen, D. Cook, P. Albertus, J. Electrochem. Soc. 160 (2013) A2258-A2267.

[53] X. Zhang, Electrochim. Acta 56 (2011) 1246-1255.

[54] U.S. Kim, C.B. Shin, C.-S. Kim, J. Power Sources 189 (2009) 841-846.

[55] C. Veth, D. Dragicevic, R. Pfister, S. Arakkan, C. Merten, J. Electrochem. Soc. 161 (2014) A1943-A1952.

[56] S. Allu, S. Kalnaus, W. Elwasif, S. Simunovic, J.A. Turner, S. Pannala, J. Power Sources 246 (2014) 876-886.

[57] L.H. Saw, Y. Ye, A.A.O. Tay, Energ. Convers. Manag. 75 (2013) 162-174.

[58] L. Fan, J.M. Khodadadi, A.A. Pesaran, J. Power Sources 238 (2013) 301-312.

[59] X.M. Xu, R. He, Renew. Sust. Energ. Rev. 29 (2014) 301-315.

[60] H. Sun, X. Wang, B. Tossan, R. Dixon, J. Power Sources 206 (2012) 349-356.

[61] C.Y. Wang, V. Srinivasan, J. Power Sources 110 (2002) 364-376.

[62] D. Bernardi, E. Pawlikowski, J. Newman, J. Electrochem. Soc. 132 (1985) 5-12. 
[63] J. Newman, K.E. Thomas, H. Hafezi, D.R. Wheeler, J. Power Sources 119-121 (2003) $838-843$.

[64] Y. Inui, Y. Kobayashi, Y. Watanabe, Y. Watase, Y. Kitamura, Energ. Convers. Manage. 48 (2007) 2103-2109.

[65] R.E. Williford, V.V. Viswanathan, J.-G. Zhang, J. Power Sources 189 (2009) 101-107.

[66] V.V. Viswanathan, D. Choi, D. Wang, W. Xu, S. Towne, R.E. Williford, J.-G. Zhang, J. Liu, Z. Yang, J. Power Sources 195 (2010) 3720-3729.

[67] N. Baba, H. Yoshida, M. Nagaoka, C. Okuda, S. Kawauchi, J. Power Sources 252 (2014) 214-228.

[68] M. Xiao, S.-Y. Choe, J. Power Sources 241 (2013) 46-55.

[69] L. Rao, J. Newman, J. Electrochem. Soc. 144 (1997) 2697-2704.

[70] Y. Chen, J.W. Evans, J. Electrochem. Soc. 141 (1994) 2947-2955.

[71] J.-S. Hong, H. Maleki, S. Al-Hallaj, L. Redey, J.R. Selman, J. Electrochem. Soc. 145 (1998) 1489-1501.

[72] S. Al-Hallaj, H. Maleki, J.S. Hong, J.R. Selman, J. Power Sources 83 (1999) 1-8.

[73] K. Onda, T. Ohshima, M. Nakayama, K. Fukuda, T. Araki, J. Power Sources 158 (2006) $535-542$.

[74] W. Lu, H. Yang, J. Prakash, Electrochim. Acta 51 (2006) 1322-1329.

[75] T.M. Bandhauer, S. Garimella, T.F. Fuller, J. Power Sources 247 (2014) 618-628.

[76] C. Forgez, D. Vinh Do, G. Friedrich, M. Morcrette, C. Delacourt, J. Power Sources 195 (2010) 2961-2968.

[77] K. Yu, X. Yang, Y. Cheng, C. Li, J. Power Sources 270 (2014) 193-200.

[78] P. Taheri, M. Yazdanpour, M. Bahrami, J. Power Sources 243 (2013) 280-289.

[79] J. Lee, K.W. Choi, N.P. Yao, C.C. Christianson, J. Electrochem. Soc. 133 (1986) 12861291.

[80] R. Mahamud, C. Park, J. Power Sources 196 (2011) 5685-5696.

[81] Z. Rao, S. Wang, G. Zhang, Energ. Convers. Manage. 52 (2011) 3408-3414.

[82] J. Hu, T. Li, J. Li, Res. J. Appl. Sci. Eng. Technol. 7 (2014) 62-71.

[83] A. Greco, D. Cao, X. Jiang, H. Yang, J. Power Sources 257 (2014) 344-355.

[84] S. Al-Hallaj, J.R. Selman, J. Power Sources 110 (2002) 341-348.

[85] C. Zhu, X. Li, L. Song, L. Xiang, J. Power Sources 223 (2013) 155-164.

[86] A. Mills, S. Al-Hallaj, J. Power Sources 141 (2005) 307-315.

[87] H. Fathabadi, J. Power Sources 245 (2014) 495-500. 
[88] R. Sabbah, R. Kizilel, J.R. Selman, S. Al-Hallaj, J. Power Sources 182 (2008) 630-638.

[89] P. Nelson, D. Dees, K. Amine, G. Henriksen, J. Power Sources 110 (2002) 349-356.

[90] R. Kizilel, A. Lateef, R. Sabbah, M.M. Farid, J.R. Selman, S. Al-Hallaj, J. Power Sources 183 (2008) 370-375.

[91] X.M. Xu, R. He, J. Power Sources 240 (2013) 33-41.

[92] S.A. Khateeb, S. Amiruddin, M. Farid, J.R. Selman, S. Al-Hallaj, J. Power Sources 142 (2005) 345-353.

[93] H.S. Hamut, I. Dincer, G.F. Naterer, Int. J. Energ. Res. 37 (2013) 1-12.

[94] G. Karimi, X. Li, Int. J. Energ. Res. 37 (2013) 13-24.

[95] L. Zhang, C. Lyu, G. Hinds, L. Wang, W. Luo, J. Zheng, K. Ma, J. Electrochem. Soc. 161 (2014) A762-A776.

[96] Y. Ye, Y. Shi, N. Cai, J. Lee, X. He, J. Power Sources 199 (2012) 227-238.

[97] W. Wu, X. Xiao, X. Huang, Electrochim. Acta 83 (2012) 227-240.

[98] K.-J. Lee, K. Smith, A. Pesaran, G.-H. Kim, J. Power Sources 241 (2013) 20-32.

[99] D.A.H. McCleary, J.P. Meyers, B. Kim, J. Electrochem. Soc. 160 (2013) A1931A1943.

[100] X. Lin, H.E. Perez, S. Mohan, J.B. Siegel, A.G. Stefanopoulou, Y. Ding, M.P. Castanier, J. Power Sources 257 (2014) 1-11.

[101] T. Wang, K.J. Tseng, S. Yin, X. Hu, in: IECON $2013-39^{\text {th }}$ Annual Conference of the IEEE Industrial Electronics Society, 2013, pp. 6709-6714.

[102] J. Vazquez-Arenas, L.E. Gimenez, M. Fowler, T. Han, S.-k. Chen, Energ. Convers. Manage. 87 (2014) 472-482.

[103] S. Santhanagopalan, P. Ramadass, J. Zhang, J. Power Sources 194 (2009) 550-557.

[104] S. Kim, H.-J. Park, J.-H. Nam, J.-H. Park, W.C. Shin, M. Ue, A safety study on internal short-circuit in $\mathrm{Li}$-ion batteries for electric vehicles, $224^{\text {th }}$ Electrochemical Society Meeting, San Francisco, USA, 2013. Abstract 540.

[105] H. Maleki, J.N. Howard, J. Power Sources 191 (2009) 568-574.

[106] W. Fang, P. Ramadass, Z. Zhang, J. Power Sources 248 (2014) 1090-1098.

[107] X. Feng, J. Sun, M. Ouyang, F. Wang, X. He, L. Lu, H. Peng, Journal of Power Sources 275 (2015) 261-273.

[108] W. Zhao, G. Luo, C.-Y. Wang, J. Electrochem. Soc. 162 (2015) A207-A217.

[109] K.-C. Chiu, C.-H. Lin, S.-F. Yeh, Y.-H. Lin, K.-C. Chen, J. Power Sources 251 (2014) 254-263. 
[110] T. Yamauchi, K. Mizushima, Y. Satoh, S. Yamada, J. Power Sources 136 (2004) 99107.

[111] S. Arnold, S. Dhaiby, S. Li, A. Jossen, Modelling short circuits in lithium-ion cells, $1^{\text {st }}$ Singapore Battery Meeting (SGBM), Singapore, 2014. Abstract p. 46.

[112] F. Ren, T. Cox, H. Wang, J. Power Sources 249 (2014) 156-162.

[113] B. Smith, Chevrolet Volt Battery Incident Overview Report, US Department of Transportation, National Highway Traffic Safety Administration, Washington DC, USA, 2012. DOT HS 811573.

[114] W.-J. Lai, M.Y. Ali, J. Pan, J. Power Sources 248 (2014) 789-808.

[115] W.-J. Lai, M.Y. Ali, J. Pan, J. Power Sources 245 (2014) 609-623.

[116] E. Sahraei, T. Wierzbicki, R. Hill, M. Luo, Crash Safety of Lithium-Ion Batteries Towards Development of a Computational Model, SAE Technical Paper 2010-011078, 2010, http://dx.doi.org/10.4271/2010-01-1078.

[117] M.Y. Ali, W.-J. Lai, J. Pan, J. Power Sources 242 (2013) 325-340.

[118] M.Y. Ali, W.-J. Lai, J. Pan, J. Power Sources 273 (2015) 448-459.

[119] E. Sahraei, R. Hill, T. Wierzbicki, J. Power Sources 201 (2012) 307-321.

[120] E. Sahraei, J. Campbell, T. Wierzbicki, J. Power Sources 220 (2012) 360-372.

[121] T. Wierzbicki, E. Sahraei, J. Power Sources 241 (2013) 467-476.

[122] E. Sahraei, J. Meier, T. Wierzbicki, J. Power Sources 247 (2014) 503-516.

[123] Y. Xia, T. Wierzbicki , E. Sahraei, X. Zhang, J. Power Sources 267 (2014) 78-97.

[124] T.D. Hatchard, D.D. MacNeil, A. Basu, J.R. Dahn, J. Electrochem. Soc. 148 (2001) A755-A761.

[125] T.D. Hatchard, D.D. MacNeil, D.A. Stevens, L. Christensen, J.R. Dahn, Electrochem. Solid-State Lett. 3 (2000) 305-308.

[126] R. Spotnitz, J. Franklin, J. Power Sources 113 (2003) 81-100.

[127] M.N. Richard, J.R. Dahn, J. Electrochem. Soc. 146 (1999) 2078-2084.

[128] M.N. Richard, J.R. Dahn, J. Power Sources 79 (1999) 135-142.

[129] N. Tanaka, W.G. Bessler, Solid State Ionics 262 (2014) 70-73.

[130] A. Du Pasquier, F. Disma, T. Bowmer, A.S. Gozdz, G. Amatucci, J.M. Tarascon, J. Electrochem. Soc. 145 (1998) 472-477.

[131] G.-H. Kim, A. Pesaran, R. Spotnitz, J. Power Sources 170 (2007) 476-489.

[132] C.F. Lopez, J.A. Jeevarajan, P.P. Mukherjee, J. Electrochem. Soc. 162 (2015) A2163A2173. 
[133] G. Guo, B. Long, B. Cheng, S. Zhou, P. Xu, B. Cao, J. Power Sources 195 (2010) 2393-2398.

[134] A. Pesaran, M. Keyser, G.-H. Kim, S. Santhanagopalan, K. Smith, Tools for designing thermal management of batteries in electric drive vehicles, Advanced Automotive Battery Conference, Pasadena, USA, 2013. NREL Report 5400-57747.

[135] A. Pesaran, G.H. Kim, K. Smith, E. Darcy, Designing safe lithium-ion battery packs using thermal abuse models, Proceedings of Lithium Mobil Power Conference, Las Vegas, USA, 2008.

[136] A. Pesaran, Energy storage R\&D: thermal management studies and modeling, DOE Hydrogen Program and Vehicle Technologies, Program Annual Merit Review and Peer Evaluation Meeting, Washington D.C, USA, 2009. NREL report PR-540-45531.

[137] P. Shack, C. Iannello, S. Rickman, R. Button, NASA Perspective and Modeling of Thermal Runaway Propagation Mitigation in Aerospace Batteries, NASA Battery Workshop 2014, NASA Aerospace Battery Workshop, Huntsville, AL, United States, 18-20 Nov. 2014, available at http://ntrs.nasa.gov/search.jsp?R=20150000860, accessed on 14.10.15.

[138] C. Yang, G.-H. Kim, S. Santhanagopalan, A. Pesaran, Multi-physics modeling of thermal runaway propagation in a Li-ion battery module, $225^{\text {th }}$ Electrochemical Society Meeting, Orlando, USA, 2014. Abstract 147.

[139] S. Abada, M. Petit, A. Lecocq, G. Marlair, V. Sauvant-Moynot, F. Huet, Examination and modeling of thermal runaway issues pertaining to new and aged Li-ion batteries, Proceedings of the $2^{\text {nd }}$ IAFSS European Symposium of Fire Safety Science, Nicosia, Cyprus, 2015. ISBN: 978-9963-2177-0-0, pp. 321-326.

[140] A. Samba, N. Omar, H. Gualous, Y. Firouz, P. Van den Bossche, J. van Mierlo, T.I. Boubekeur, Electrochim. Acta 117 (2014) 246-254.

[141] M. Fleckenstein, S. Fischer, O. Bohlen, B. Bäker, J. Power Sources 223 (2013) 259267.

[142] E. Barsoukov, J.H. Jang, H. Lee, J. Power Sources 109 (2002) 313-320.

[143] ASTM E1225-13, Standard test method for thermal conductivity of solids using the guarded-comparative-longitudinal heat flow technique, ASTM International, West Conshohocken, PA, 2013.

[144] ASTM E1461-13, Standard test method for thermal diffusivity by the flash method, ASTM International, West Conshohocken, PA, 2013. 
[145] A. Arzberger, M. Hellenbrand, D.U. Sauer, Operating point dependent thermal parameterization of cylindrical lithium ion cells, $11^{\text {th }}$ Symposium on Fuel Cell and Battery Modeling and Experimental Validation, Winterthur, Switzerland, 2014. Abstract 147.

[146] S.C. Nagpure, R. Dinwiddie, S.S. Babu, G. Rizzoni, B. Bhushan, T. Frech, J. Power Sources 195 (2010) 872-876.

[147] W.J. Parker, R.J. Jenkins, C.P. Butler, G.L. Abbott, J. Appl. Phys. 32 (1961) 16791684.

[148] S. Al-Hallaj, J. Prakash, J.R. Selman, J. Power Sources 87 (2000) 186-194.

[149] K. Onda, H. Kameyama, T. Hanamoto, K. Ito, J. Electrochem. Soc. 150 (2003) A285A291.

[150] K.E. Thomas, J. Newman, J. Power Sources 119-121 (2003) 844-849.

[151] Ph. Biensan, B. Simon, J.-P. Pérès, A. de Guibert, M. Broussely, J.M.. Bodet, F. Perton, J. Power Sources 81-82 (1999) 906-912.

[152] J.-I. Yamaki, H. Takatsuji, T. Kawamura, M. Egashira, Solid State Ionics 148 (2002) $241-245$.

[153] E.P. Roth, D.H. Doughty, J. Franklin, J. Power Sources 134 (2004) 222-234.

[154] H. Maleki, G. Deng, A. Anani, J. Howard, J. Electrochem. Soc. 146 (1999) 32243229.

[155] Y. Baba, S. Okada, J.-I. Yamaki, Solid State Ionics 148 (2002) 311-316.

[156] R. Venkatachalapathy, C.W. Lee, W. Lu, J. Prakash, Electrochem. Commun. 2 (2000) $104-107$.

[157] C. Capiglia, J. Yang, N. Imanishi, A. Hirano, Y. Takeda, O. Yamamoto, J. Power Sources 119-121 (2003) 826-832.

[158] S.E. Sloop, J.K. Pugh, S. Wang, J.B. Kerr, K. Kinoshita, Electrochem. Solid-State Lett. 4 (2001) A42-A44.

[159] G.G. Botte, R.E. White, Z. Zhang, J. Power Sources 97-98 (2001) 570-575.

[160] T. Kawamura, A. Kimura, M. Egashira, S. Okada, J.-I. Yamaki, J. Power Sources 104 (2002) 260-264.

[161] D.P. Abraham, E.P. Roth, R. Kostecki, K. McCarthy, S. MacLaren, D.H. Doughty, J. Power Sources 161 (2006) 648-657.

[162] G. Nagasubramanian, K. Fenton, Electrochim. Acta 101 (2013) 3-10. 
[163] J.S. Gnanaraj, E. Zinigrad, L. Asraf, H.E. Gottlieb, M. Sprecher, D. Aurbach, M. Schmidt, J. Power Sources 119-121 (2003) 794-798.

[164] M. Tabaddor, A. Wu, C. Wang, B.-J. Hwang, J.-H. Chen, Study of polarization effect and thermal stability in aged lithium-ion battery, $3^{\text {rd }}$ Annual International Conference on Battery Safety 2012, Las Vegas, USA, 2012. ISBN: 978-1-62276-845-5, pp. 83-98.

[165] M. Fleischhammer, T. Waldmann, G. Bisle, B.-I. Hogg, M. Wohlfahrt-Mehrens, J. Power Sources 274 (2015) 432-439.

[166] P. Ribière, S. Grugeon, M. Morcrette, S. Boyanov, S. Laruelle, G. Marlair, Energy Environ. Sci. 5 (2012) 5271-5280.

[167] G.G. Eshetu, J.-P. Bertrand, A. Lecocq, S. Grugeon, S. Laruelle, M. Armand, G. Marlair, J. Power Sources 269 (2014) 804-811.

[168] A.-O. Diallo, A.B. Morgan, C. Len, G. Marlair, Energy Environ. Sci. 6 (2013) 699710.

[169] L. Chancelier, A.O. Diallo, C.C. Santini, G. Marlair, T. Gutel, S. Mailley, C. Len, Phys. Chem. Chem. Phys. 16 (2014) 1967-1976.

[170] J.B. Robinson, J.A. Darr, D.S. Eastwood, G. Hinds, P.D. Lee, P.R. Shearing, O.O. Taiwo, D.J.L. Brett, J. Power Sources 252 (2014) 51-57.

[171] D.P. Finegan, M. Scheel, J.B. Robinson, B. Tjaden, I. Hunt, T.J. Mason, J. Millichamp, M. Di Michiel, G.J. Offer, G. Hinds, D.J.L. Brett, P.R. Shearing, Nat. Commun. 6 (2015) Article number: 6924. http://dx/doi.org/10.1038/ncomms7924.

[172] Q. Wang, P. Ping, X. Zhao, G. Chu, J. Sun, C. Chen, J. Power Sources 208 (2012) $210-224$.

[173] T.D. Hatchard, S. Trussler, J.R. Dahn, J. Power Sources 247 (2014) 821-823.

[174] T. Ohsaki, T. Kishi, T. Kuboki, N. Takami, N. Shimura, Y. Sato, M. Sekino, A. Satoh, J. Power Sources 146 (2005) 97-100.

[175] D. Belov, M.-H. Yang, Solid State Ionics 179 (2008) 1816-1821.

[176] H. Maleki, J.N. Howard, J. Power Sources 137 (2004) 117-127.

[177] H. Maleki, J.N. Howard, J. Power Sources 160 (2006) 1395-1402.

[178] C. Mikolajczak, M. Kahn, K. White, R.Th. Long, Lithium-Ion Batteries Hazard and Use Assessment, SpringerBriefs in Fire, http://dx/doi.org/10.1007/978-1-4614-3486-3, Springer, New York, USA, 2011.

[179] Y. Zeng, K. Wu, D. Wang, Z. Wang, L. Chen, J. Power Sources 160 (2006) 13021307. 
[180] S. Erol, M.E. Orazem, R.P. Muller, J. Power Sources 270 (2014) 92-100.

[181] G. Crabtree, AIP Conf. Proc. 1652 (2015) 112-128. http://xxx.tau.ac.il/abs/1411.7042, accessed on 12.07.15.

[182] Research network on electrochemical energy storage, RS2E, http://www.energiers2e.com/en, accessed on 12.07.15.

[183] T. Husch, N.D. Yilmazer, A. Balducci, M. Korth, Phys. Chem. Chem. Phys. 17 (2015) 3394-3401.

[184] A. Pesaran, G.H. Kim, K. Smith, K.J. Lee, S. Santhanagopalan, Computer-Aided Engineering of Batteries for Designing Better Li-Ion Batteries, $12^{\text {th }}$ Advanced Automotive Battery Conference, Orlando, USA, 2012. NREL PR-5400-53777, http://www.nrel.gov/docs/fy12osti/53777.pdf, accessed on 14.07.15. 
Table 1: Incidents related to LIBs (adapted and completed from [8,11] and from information available on different internet websites).

\begin{tabular}{|c|c|c|}
\hline Date / place & Type of application & Incident summary \\
\hline April, 2011 / Hangzhou, China & Zotyc M300 EV & $\begin{array}{l}\text { internal short circuit in defective battery pack due to insulation damage } \\
\text { between battery cells and walls of the aluminum container }\end{array}$ \\
\hline $\begin{array}{l}\text { June, } 2011 \text { / National highway traffic } \\
\text { safety administration (USA) }\end{array}$ & Chevrolet volt EV & fire occurred 3 weeks after a crash test \\
\hline May, 2012 / Shenzhen (China) & $\begin{array}{l}\text { Nissan GT-R EV } \\
\text { in BYD e6 taxi }\end{array}$ & $\begin{array}{l}\text { electric arcs caused by short-circuit of high voltage distribution lines and } \\
\text { car body ignited combustible material in the vehicle }\end{array}$ \\
\hline $\begin{array}{l}\text { January 7, } 2013 \text { / Japan airlines } \\
\text { Boston's Logan International Airport }\end{array}$ & $\begin{array}{l}\text { aircraft battery } \\
\text { (Boeing } 787 \text { Dreamliner) }\end{array}$ & Battery overheated and started a smoky fire \\
\hline January 16, 2013 / All Nippon Airways & aircraft battery & error message indicating a battery malfunction, and odd smell detected in \\
\hline Takamatsu Airport on Shikoku Island & (Boeing 87-8 model) & the cockpit and cabin \\
\hline $\begin{array}{l}\text { March 18, } 2013 \text { / Mitsubishi motors } \\
\text { Mizushima battery pack assembly plant }\end{array}$ & Mitsubishi i-MiEV & $\begin{array}{l}\text { the lithium-ion battery of an i-MiEV caught fire while connected to a } \\
\text { charge-discharge test equipment }\end{array}$ \\
\hline March, 2013 / Mitsubishi motors & Outlander P-HEV & the battery pack of an Outlander P-HEV overheated and melted some of \\
\hline Dealership in Yokohama & Mitsubishi motors & the battery cells after vehicle had been fully charged and stood for 1 day \\
\hline $\begin{array}{l}\text { October 1, } 2013 \text { / Kent, Washington } \\
\text { (USA) }\end{array}$ & Tesla Model S & $\begin{array}{l}\text { fire in the Model S battery pack caused by the direct impact of a large } \\
\text { metallic object to one of the } 16 \text { modules within the pack }\end{array}$ \\
\hline October 18, 2013 / Merida, Mexico & Tesla Model S & crash of a vehicle driven at high speed through a roundabout \\
\hline $\begin{array}{l}\text { November 6, } 2013 \text { / Interstate } 24 \text { near } \\
\text { Murfreesboro, Tennessee }\end{array}$ & Tesla Model S & $\begin{array}{l}\text { the Model S struck a tow hitch on the roadway, causing damage beneath } \\
\text { the vehicle }\end{array}$ \\
\hline February 2014 / Toronto, Canada & Tesla Model S & fire started when the car was parked in garage, not plugged in and charging \\
\hline
\end{tabular}


Table 2: 1D electrochemical model equations. [27, 28]

Physical and

chemical mechanisms
Eq.

$$
\frac{\partial}{\partial t} c_{\mathrm{S}}-\frac{1}{r^{2}} \frac{\partial}{\partial r}\left(r^{2} D_{\mathrm{s}} \frac{\partial}{\partial r} c_{\mathrm{S}}\right)=0
$$

$$
\begin{gathered}
\left.D_{\mathrm{s}} \frac{\partial}{\partial r} c_{\mathrm{s}}\right|_{r=0}=0 \\
-\left.D_{\mathrm{s}} \frac{\partial}{\partial r} c_{\mathrm{s}}\right|_{r=R_{\mathrm{S}}}=\frac{j^{\mathrm{Li}}}{a_{\mathrm{s}} F}
\end{gathered}
$$

$$
\left.\frac{\partial}{\partial x} c_{\mathrm{e}}\right|_{x=0}=\left.\frac{\partial}{\partial x} c_{\mathrm{e}}\right|_{x=L}=0
$$

of $\mathrm{Li}^{+}$species

Solid phase:

charge conservation

$$
\frac{\partial}{\partial x}\left(\sigma^{\text {eff }} \frac{\partial}{\partial x} \phi_{\mathrm{s}}\right)-j^{\mathrm{Li}}=0
$$

$$
\begin{gathered}
-\left.\sigma_{\mathrm{n}}^{\mathrm{eff}} \frac{\partial}{\partial x} \phi_{\mathrm{s}}\right|_{x=0}=-\left.\sigma_{\mathrm{p}}^{\mathrm{eff}} \frac{\partial}{\partial x} \phi_{\mathrm{s}}\right|_{x=L}=\frac{I}{A} \\
\left.\frac{\partial}{\partial x} \phi_{\mathrm{s}}\right|_{x=\delta_{-}}=\left.\frac{\partial}{\partial x} \phi_{\mathrm{s}}\right|_{x=L-\delta_{+}}=0
\end{gathered}
$$

$$
\left.\frac{\partial}{\partial x} \phi_{\mathrm{e}}\right|_{x=0}=\left.\frac{\partial}{\partial x} \phi_{\mathrm{e}}\right|_{x=L}=0
$$

charge conservation

$$
\frac{\partial}{\partial x}\left(\kappa^{\mathrm{eff}} \frac{\partial}{\partial x} \phi_{\mathrm{e}}\right)+\frac{\partial}{\partial x}\left(\kappa_{\mathrm{D}}^{\mathrm{eff}} \frac{\partial}{\partial x} \ln c_{\mathrm{e}}\right)+j^{\mathrm{Li}}=0
$$

kinetics

$$
\begin{array}{r}
j^{\mathrm{Li}}=a_{\mathrm{S}} i_{0}\left\{\exp \left(\frac{\alpha_{\mathrm{ox}} F}{R T}\left(\phi_{\mathrm{s}}-\phi_{\mathrm{e}}-U\right)\right)-\exp (\right. \\
\eta=\phi_{\mathrm{s}}-\phi_{\mathrm{e}}-U
\end{array}
$$

overpotential

$$
D_{\mathrm{e}}^{\mathrm{eff}}=D_{\mathrm{e}} \varepsilon_{\mathrm{e}}^{\text {Brugg }}
$$

diffusivity

$$
\kappa^{\mathrm{eff}}=\kappa \varepsilon_{\mathrm{e}}^{\text {Brugg }}
$$

conductivity

$$
\kappa_{\mathrm{D}}^{\mathrm{eff}}=\frac{2 R T \kappa^{\mathrm{eff}}}{F}\left(t_{+}-1\right)\left(1+\frac{d \ln f_{ \pm}}{d \ln c_{\mathrm{e}}}\right)
$$

diffusional

conductivity

Solid phase electronic conductivity

$$
\sigma^{\text {eff }}=\varepsilon_{\mathrm{S}} \sigma
$$

Specific interfacial

surface area

$$
a_{\mathrm{S}}=\frac{3 \varepsilon_{\mathrm{S}}}{R_{\mathrm{S}}}
$$




\begin{tabular}{|c|c|c|c|}
\hline $\begin{array}{c}\text { Main SEI } \\
\text { formation reaction }\end{array}$ & solvent $+2 \mathrm{e}^{-}+2 \mathrm{Li}^{+} \rightarrow \mathrm{SEI}$ & (15) & \\
\hline $\begin{array}{l}\text { Tafel kinetics for } \\
\text { solvent reduction } \\
\text { reaction }\end{array}$ & $i_{\mathrm{s}}=-F k_{\mathrm{f}} c_{\mathrm{solv}}^{*} \exp \left(-\frac{\beta F}{R T}\left(\phi_{\mathrm{s}, \mathrm{n}}-\frac{\delta_{\mathrm{SEI}}}{\kappa_{\mathrm{SEI}}} i_{\mathrm{t}}\right)\right.$ & (16) & \\
\hline $\begin{array}{l}\text { Current balance for } \\
\text { the negative } \\
\text { electrode }\end{array}$ & $i_{\mathrm{t}}=i_{\text {int }}+i_{\mathrm{s}}$ & (17) & $-\left.D_{\mathrm{s}} \frac{\partial}{\partial r} c_{\mathrm{s}}\right|_{r=R_{\mathrm{s}, \mathrm{n}}}=\frac{j_{\mathrm{n}}^{\mathrm{Li}}}{a_{\mathrm{s}, \mathrm{n}} F}$ \\
\hline $\begin{array}{c}\text { Mass balance for } \\
\text { solvent }\end{array}$ & $\frac{\partial c_{\text {Solv }}}{\partial t}=D_{\text {solv }} \frac{\partial^{2} c_{\text {Solv }}}{\partial r^{2}}-\frac{d \delta_{\text {SEI }}}{d t} \frac{\partial c_{\text {Solv }}}{\partial r}$ & (18) & $-\left.D_{\mathrm{solv}} \frac{\partial c_{\mathrm{solv}}}{\partial r}\right|_{r=R_{\mathrm{s}, \mathrm{n}}}$ \\
\hline $\begin{array}{l}\text { Growth rate of the } \\
\text { SEI layer }\end{array}$ & $\frac{d \delta_{\mathrm{SEI}}}{d t}=-\frac{i_{\mathrm{S}} M_{\mathrm{SEI}}}{2 F \rho_{\mathrm{SEI}}}$ & (19) & $\begin{array}{c}+\frac{d \delta_{\mathrm{SEI}}}{d t} c_{\mathrm{Solv}}^{*}=\frac{i_{\mathrm{S}}}{F} \\
\left.c_{\mathrm{Solv}}\right|_{r=R_{\mathrm{s}, \mathrm{n}}+\delta_{\mathrm{SEI}}}=\varepsilon_{\mathrm{SEI}} c_{\mathrm{Solv}}^{\mathrm{b}}\end{array}$ \\
\hline
\end{tabular}




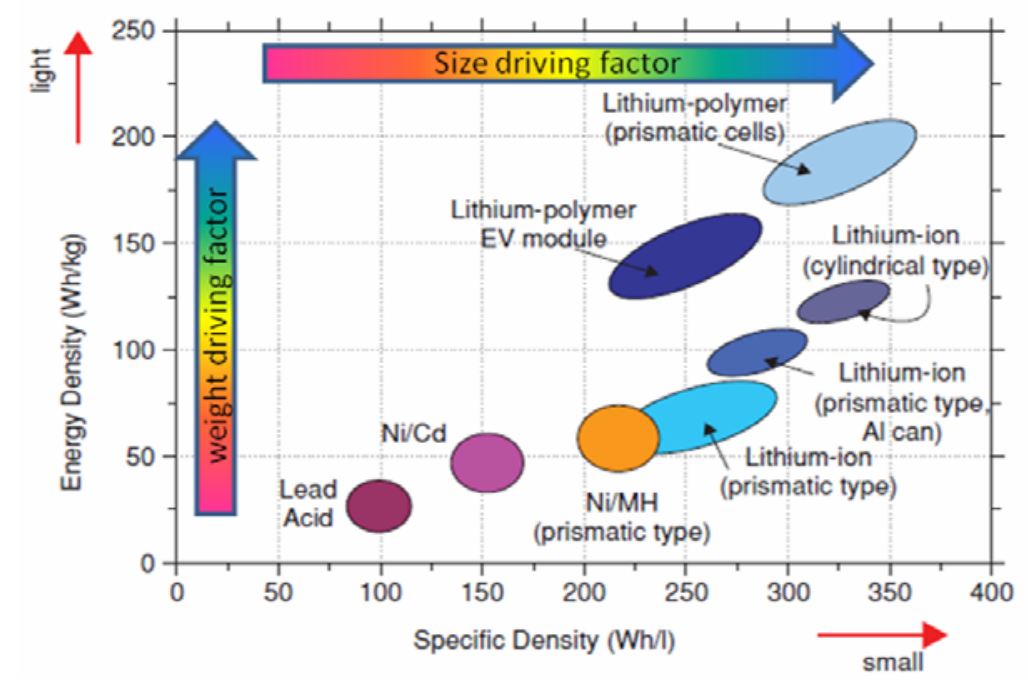

Figure 1: Energy density (Wh/kg) vs. specific density $(\mathrm{Wh} / \mathrm{L})$ diagram for a series of batteries (adapted from ref. [2])

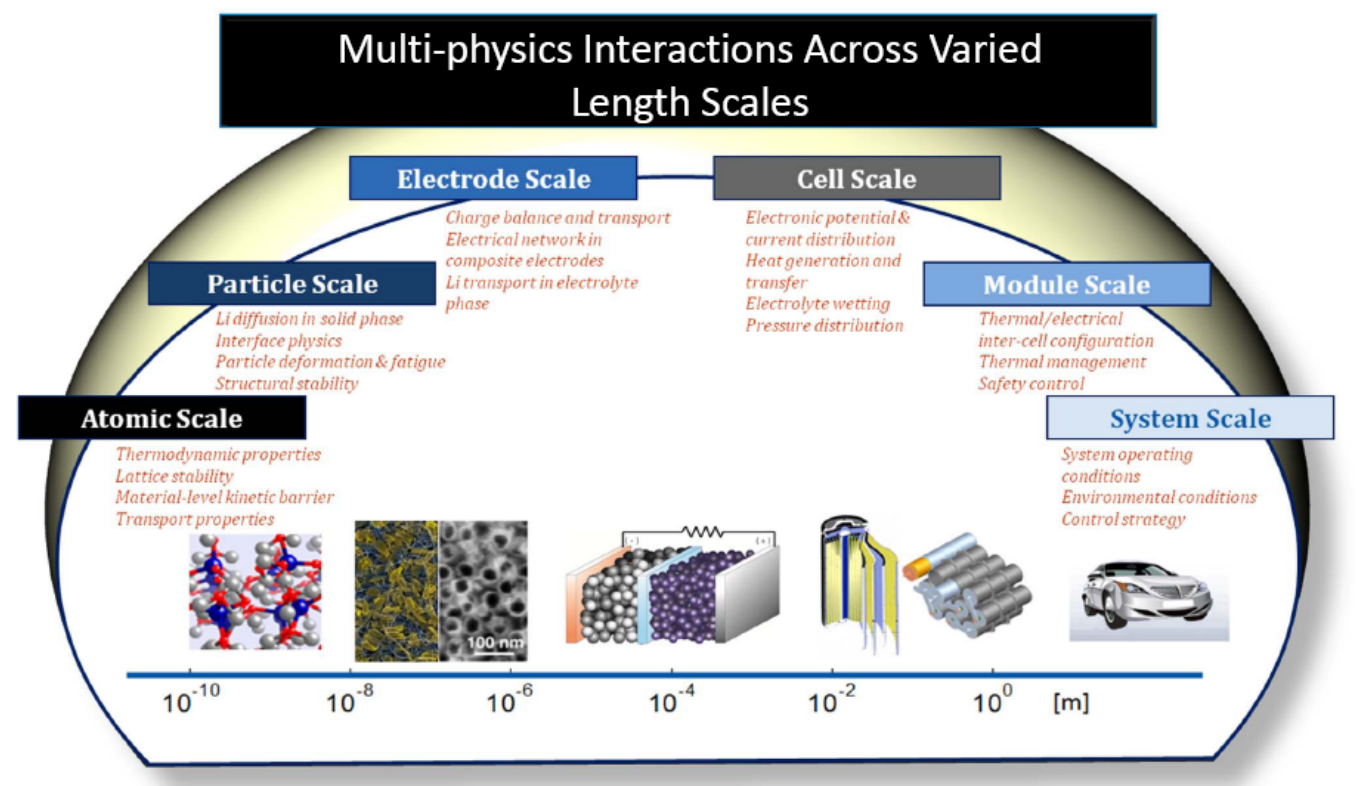

Figure 2: Length scale dependent physics impacting battery modeling (after NREL [184]) 


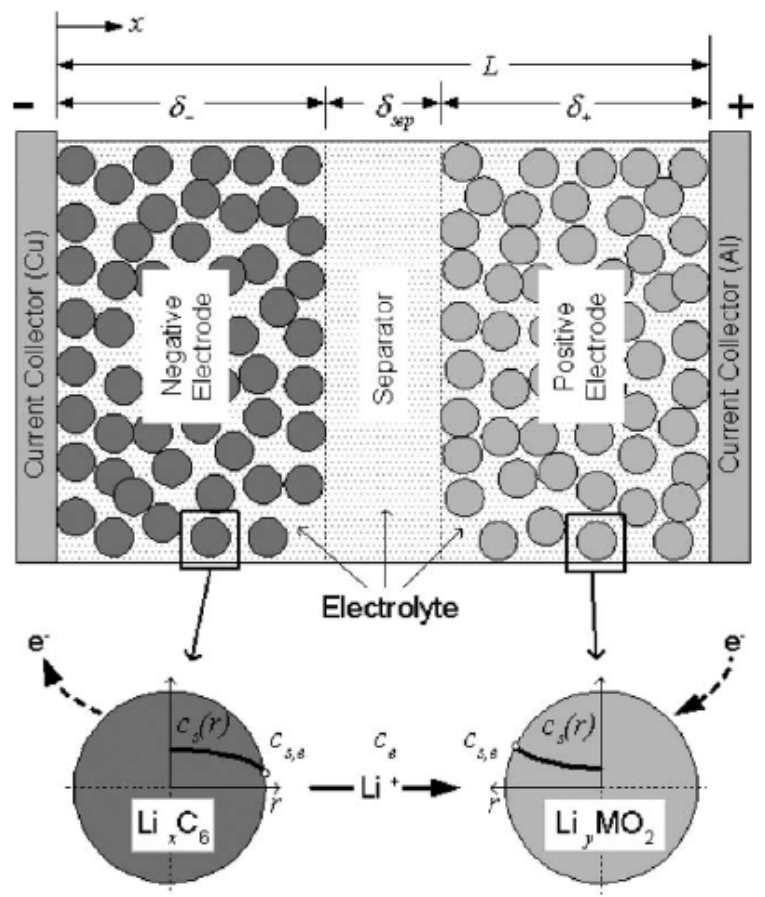

Figure 3: Diagram of 1D (x-direction) electrochemical cell model with coupled 1D microscopic (r-direction) solid diffusion model (reproduced from ref. [28]).

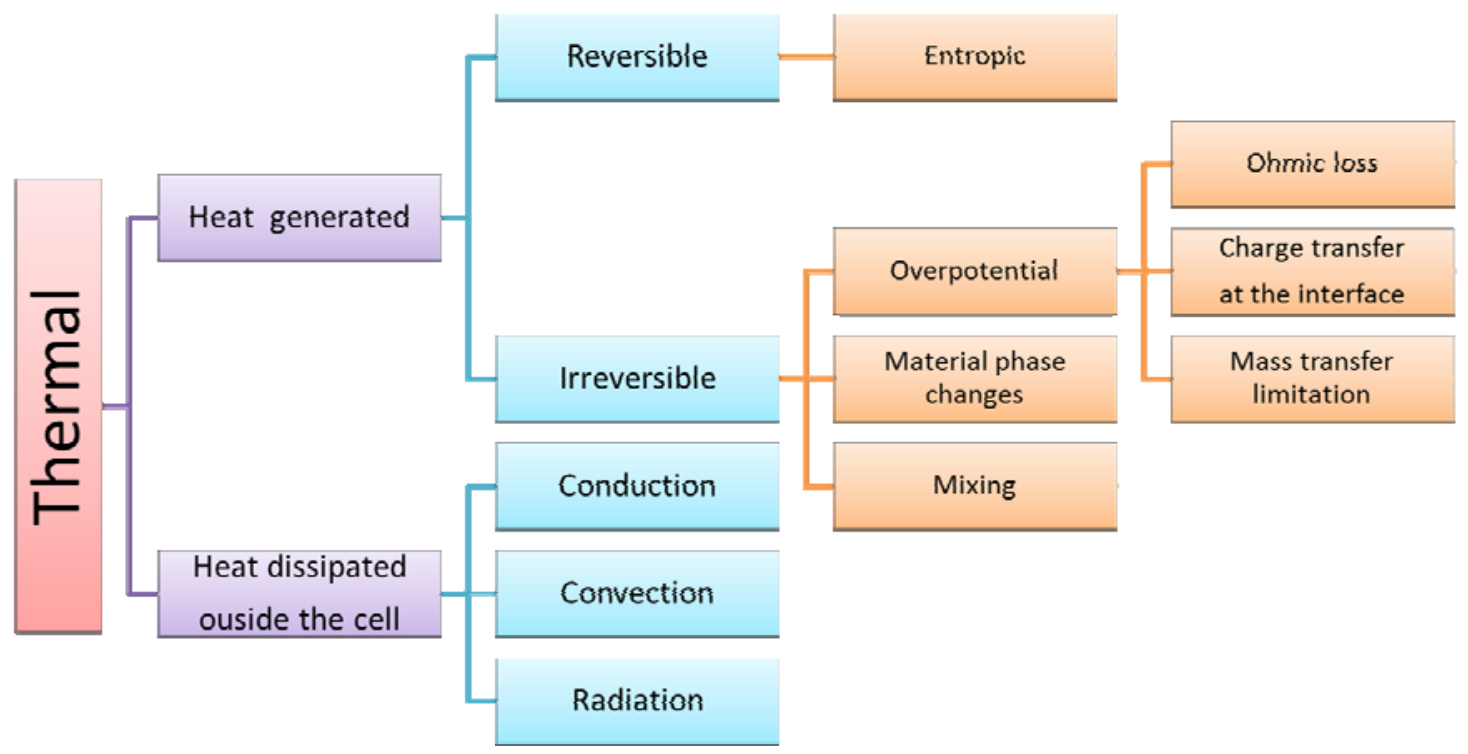

Figure 4: Thermal modeling approaches of LIBs. 

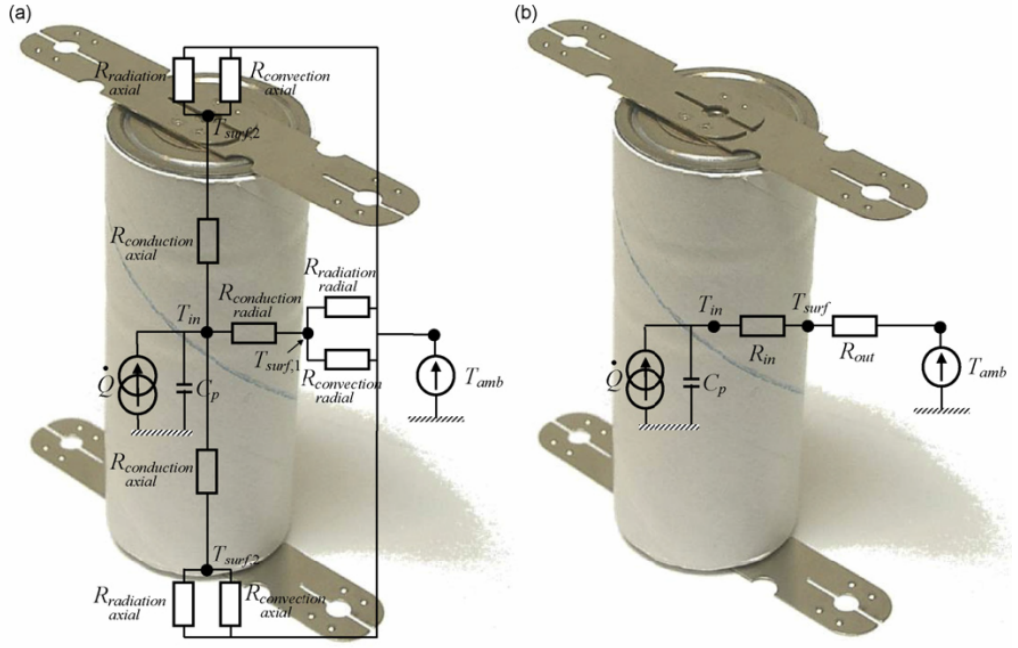

Figure 5: Forgez et al.'s Lumped models (a) complete model (b) simplified equivalent circuit model (adapted from ref. [76]) 